\title{
17th Annual Meeting
}

\section{European Society for Paediatric Gastroenterology and Nutrition}

\author{
Tampere, Finland \\ June 27-29, 1984
}

IHE PASSAGE OF ORALLY OR INTRAVENOUSLY ADMINISTERED PROTEINS FROM MOTHER TO FOETUS" AND TO THE MILK OF THE RAT.

E. Telemo, G.M.K. Dahl, B.R. Weström, I. Jakobsson, B.W. Karlsson and T. Lindberg Dept. of Zoophysiology, University of Lund Sweden and Dept. of Paediatrics and Experimental Research, University of Lund, Malmö General Hospital, Malmö.

Pregnant or lactating rats were given via oral or intravenous routes a test solution containing various marker proteins. Using immunoprecipitation methods for the detection of $\beta$-lactoglobulin $(B-L G)$, ovalbumin (OVA), bovine serum albumin (BSA) and bovine gammaglobulins (BIgG) and in addition radioimmunoassay for the analysis of $\beta-L G$, these proteins were found in the maternal blood serum, the uterine and amniotic fluid and in the bloodserum of the foetuses in the pregnant group of rats. In the lactating group of rats the protein were found in serum and milk, with a specific distribution pattern between the serum and the milk for each protein. The results showed that orally fed dietary proteins are able to cross the gut of the pregnant and lactating rat and can be found in the fetuses and the milk. It was a?so observed that oral feeding of the proteins resulted in relatively greater concentrations in the fetuses and the milk, than did intravenous administration. This very early presentation to the young of antigenic macromolecules derived from the mothers diet, might be of importance for the development of a proper immunological response to common food antigens.

FOOD ANTIGENS IN BREAST HILK, A ROLE IN IMUEDIATE HYPERSEINSITIVITY, ECZEM \& COLITIS IN FULLY BREAST FED INFANTS? A.J. Cant, P.J. Kilshaw, J.A. Bailes R.A. Marsden Depts. of Child Health \& Dermatology St. George's Hospital Medical School, London, sull Eczema in breast fed infants is reputed to be caused by food
proteins transmitted through mothers' milk. By sensitive radioproteins transmitted through mothers' milk. By sensitive radioimmunoassay we have identified traces of cows' milk and egg protheir solely breast fed infants were further investigated. 19 infants had definite eczema, 14 possible eczema, 12 (controls) no rash; all were skin pricl: tested against 6 food antigens. Mothers of 12 eczematous infants and 8 controls had standard milk/egg challenges followed by analysis of their milk for ovalbumin. 18 mothers with eczematous infants completed a double-blind controlled dietary trial of cows' milk and egg exclusion.

$12 / 19$ infant's with definite eczema had +ve skin tests to cows' mille or egg, 1/14 with possible eczema reacted to egg, no control was +ve. Ovalbumin was detected in milk of $\frac{3}{4}$ of mothers tested in both eczema and control groups with no correlation between antigen levels and presence of infant eczema. In $14 / 18$ infants of mothers in the dietary trial exclusion of cows' milk/egg was ineffective; in 4 exclusion was effective and challenge provoked eczema in all, with diarrhoea in 2 . Thus although 60\% of eczematous breast fed infants show immediate skin sensitivity to cows' milk or egg protein only $20 \%$ improve if mothers avoid these foods.
BOVINE $\boldsymbol{\beta}$-LACTOGLOBULIN IN HUMAN MILK

3 I. Jakobsson, I. Lindberg, B. Benediktsson. Dept. of Paediatrics and Experimental Research, University of Lund, Malmö General Hospital, S-214 01 Malmö, Sweden. It has been recognized for 50 years that substances can pass from mother to infant via the breastmilk and cause adverse reactions in the infant, but very few, if any, substances have been identified. We have shown that infantile colic in breastfed infants can be related to the mothers' cow's milk protein consumption. The aim of this investigation was to study if bovine 1 lactoglobulin is present in human milk and if the presence could be related to symptoms of colic in the infant. Human milk was randomly obtained from 35 mothers with healthy infants and from 3 mothers whose infants had colic related to the mothers' cow's milk consumption. $\boldsymbol{\beta}$-lactoglobulin was determined with a competitive radioimmunoassay. $5 \mathrm{\mu g} / 1$ or more could be detected. In 18/38 samples of human milk there were measureble amounts. 12 samples contained 5 to $10 \mathrm{\mu q} / 1$, three contained 33,25 and $25 \mathrm{mg} / \mathrm{l}$. The milk from 3 mothers with colicky infants contained 32 , 18 , and $14 \mathrm{\mu g} / 1$. On a cow's milk free diet two of the three mothers had $\mathbf{S} \mathrm{\mu g} / \mathrm{l}$ of $\mathbf{\beta}$-lactoglobulin, the $3 \mathrm{rd}$ had $6 \mathrm{\mu g} / \mathrm{l}$. All three infants bacame free of colic. In conclusion: human milk can contain bovine $\boldsymbol{\beta}$-lactoglobulin and symptoms of infantile colic in breastfed infants can be related to the presence of bovine $\boldsymbol{\beta}$-lactoglobulin in human milk.

1. Jakobsson I., Lindberg T.: Pediatrics 71, 268, 1983.

\section{P. Forget, F. Sodoyez-Goffaux. Dept. Paediatrics,}

An increased gut permeability to macromolecules is thought to be an important factor in the development of food allergy of either primary or secondary type. The latter is supposed to develop during the course of acute gastroenteritis or other diseases associated with intestinal mucosal damage.

$5^{1-}$ Cr EDTA has recently been shown to be a most sensitive marker of gut permeability (1).

We investigated gut permeability in 11 control children, 7 patients with healing gastroenteritis and 7 patients with eczema. ${ }^{51}-\mathrm{Cr}$ EDTA $(50 \mu \mathrm{H}$ ) was administered orally, urinary excretion of $51-\mathrm{Cr}$ EDTA was measured during the following 24 hours and expressed as percentage of oral dose.

The range of results were $0.77-3.4 ; 3.4-29.6$ and $6.5-$ 22.8 for controls, gastroenteritis and eczema patients respectively. Differences between controls and either gastroenteritis $(\mathrm{p}<0.001)$ or eczema $(\mathrm{p}<0.01)$ patients are significant. Our results support the hypothesis that an increased gut permeability is an important factor in the development of food allergy.

(1) Ingvar Bjarnason et al., Lancet, 1, 323, 1983. 
INTESTINAL SUGAR PERMEABILITY IN DIARRHOEAL DISEASE AND ITS POTENTIAL IN GASTROINTESTINAL FOOD ALIERGY. RPK Ford, IS Menzies, JA Walker-Smith, AD Phillips \& MW Turner. Queen Elizabeth Hospital for Children, Institute of Child Health \& St Thomas' Hospital, LONDON. bowel integrity. Permeability was measured by the differential absorntion of lactulase and L-rhamnose in 39 children(2 to $19 \mathrm{~m}$ ) with diarrhoeal il zness, in 28 ( $3 \mathrm{~m}$ to $15 \mathrm{y}$ ) within $48 \mathrm{~h}$ of small bowel biopsy, and in $9(1 \mathrm{~m}$ to $3 \mathrm{y})$ with gastrointestinal milk hypersensitivity. An oral isotonic load containing $3.5 \mathrm{~g}$ lactulose and $0.5 \mathrm{~g} \mathrm{~L}$-rhamnose was given.Urine concentrations were determined by quantitative thin layer chromatography. Lactulose/L-rhamnose excretion ratios in children with acute gastroenteritis (mean $0.43 \pm \mathrm{sd0} .31, \mathrm{n}=15$ )were significantly higher than those with chronic diarrhoea $0.12+.074, n=14)$, $\mathrm{p}<.01$, Wilcoxon rank sum.Ratios of both groups were higher than a control group $(0.045 \pm .018, n=15), p<.01$. The overall correlation between

permeability and proximal small bowel morphology was high, $r=.65$ $\mathrm{n}<.01$. Children with gastrointestinal milk hypersensitivity had control group,p<.01. The permeability of 2 out of 3 symptomatic children was abnormal on milk but returned to normal when milk was again eliminated.This test of intestinal permeability seems to be clinically relevant and has great potential in the investigation and management of food allergic disease.
Intestinal permeability appears to be a promising test of small pre-challenge permeability ratios $(0.10 \pm .089, \mathrm{n}=8)$ higher than the

CITROBACTER(C.): A HEAT-STABLE ENTEROTOXIN(ST)PRODUCING ENTERIC PATHOGEN. A.Guarino,G.Capano,B.Malamisura, M. Alessio,S.Guandal ini, A.Rubino.Inst.Ped.2nd Sch.Med.Univ. Naples, Italy.

Beyond identification of "classical"pathogens by means of stool cul tures, the detection of enterotoxigenicity has a more general role of possible recognition of the pathogenetic mechanism involved. $C$. is regarded as a common component of intestinal microflora. Nonethe less some strains of heat-labile enterotoxin(LT)producing C.have be en isolated from children with diarrhea.To ascertain the role of enterotoxigenic C.as a possible agent of diarrhea,we looked for the presence of both LT(by the Biken test) and ST(by suckling mouse assay (SMA)) in every C.isolated from the stools of 328 children( 1 month-3years of age) consecutively admitted because of diarrhea.92
children without G.I.complaints matched for age served as control. All known pathogens, including ETEC and Rotavirus, were looked for in every child. Results: C. was found in the stools of 46 patients with diarrhea(14\%) and in 7 of the controls $(7.6 \%)$. None of the $C$. strains produced LT.In the controls, no ST production either was fo und. In the group with diarrhea, 3 strains, all isolated from infants with acute,mild diarrhea, in whom no other etiology was identified, were found repeatedly positive at the SMA for ST with the intestine/carcass weight ratio $>0.085$. Further experiments by the SMA show ed a time-course effect similar to the E.COIi ST.The secretagogue activity of a partially purified preparation of such ST was further more confirmed in the vivo rat jejunum. In conclusion:we suggest that C.may act as an enteric pathogen in children,by producing an ST. Further investigations are being carried out to better define its mechanism of action.

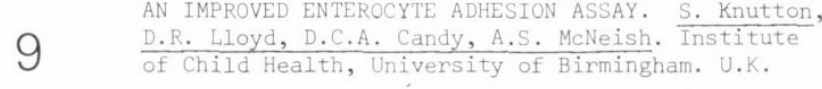
INTESTINAL PERMEABILITY IN IMMUNODEFICIENT PATTENTS ASSESSED WITH DIFFERENTLY B.S. Lindblad ${ }^{1}, 2$, C. Cunningham-Rundles,$K$. - E. MagStockholm, Sweden, 2Dept. Immunobiology, Memorial Sloan-Kettering Cancer Center, New York, USA, 3Dept. Medical Microbiology, Univ. of Linköping, Sweden

The intestinal permeability was studied in 14 immunodeficient subjects suffering from common variable immunodeficiency (CVI) or selective IgA deficiency. Different-sized polyethyleneglycols sizing between 282 and 1250 dalton were used as probe molecules. It was found that the patients after a liquid meal of probes displayed a reduced 6-hour urinary recovery of the smaller PEGs, i.e. sizing around 370-414 dalton, but an increased recovery of the larger PEGs which are around 1974-1118 dalton. After adapting the recovery of PEGs to a mathematical filter function describing intestinal exclusion due to size it is proposed that immunodeficient patients are characterized by an impaired absorptive capacity of small molecules, indicative of a reduced surface area, and by increased permeation of larger molecules, i.e. passive leakage of any material. These findings may help understanding that CVI and IgA deficiency in particular is associated with elevated levels of circulating immune complexes with various food antigens. They may also have a bearing on the immune function of the immature intestine before a local mucosal IgA-dependent humoral defense system has developed.

INTESTINAL ANTIGEN HANDLING: SIMILAR CHANGES IN LACTATING AND NEWBORN RATS, M,Stern and W.A.Walker Harvard Medical Sohool, Mass.Gen. Hospital, Dept. of Pediatrics, Boston, USA To study intestinal host defense in newborns and in their lactating mothers, microvillus membrane (MVM) preparations and everted gut sacs were used as models of binding and uptake of $125 \mathrm{I}-1$ abelled bovine serum albumin (BSA). Although newborn MVM showed more BSA binding than adult controls $(0.84 \pm 0.31$ vs $0.15 \pm 0.16$ ug $\mathrm{BSA}$ equivalents/mg mucosal protein, p<0.001), binding to the mucous coat of gut sacs from 18 day old breastfed animals was significantly less, compared to adults $(0.94 \pm 0.30$ vs $3.06 \pm 0.74, p<0.001)$. The same was true for uptake. In lactating mothers, also less mucous coat binding and uptake by gut sacs were observed, compared to nonlactating controls (BSA binding $1.48 \pm$ 0.27 vs $3.06 \pm 0.74$; uptake $0.12 \pm 0.03$ vs $0.71 \pm 0.20$, p4 $0.001)$. It was shown that these corresponding changes were not due to oral immunization. These data suggest that immature animals and their lactating mothers are binding less BSA to the jejunal mucous coat than controls, and that both groups are taking up less. Protective elements like the mucus layer might be instrumental in antigen handling to decrease exposure of the jejunal surface membrane in both, lactating rats and their suckling litters.
CLINICAL PROTECTION STUDIES OF A LIVE ATTENUATED ORAL ROTAVIRUS VACCINE OF BOVINE ORIGIN (RIT 4237 STRAIN). T.Vesikari, E.Isolauri, E.d'Hondt, A.Delem, F.E.André, G.Zissis. Dept. Clinical Sciences, University of Tampere, Tampere, Finland

After completion of imunogenicity and safety testing in adults and young children the RIT 4237 rotavirus vaccine was evaluated for clinical efficacy in infants. In a double-blind placebo-controlled trial 178 infants aged 8 to 11 months received a single oral vaccination and remained in clinical and serological follow-up for an epidemic season of rotavirus. No side effects atcases of clinically significant rotavirus diarrhoea among the 86 vaccine recipients as compared to 18 cases among the 92 placebo recipients ( $<<0.001)$; the 2 cases in the vaccine group occurred in children who failed to seroconvert after vaccination. The protection rate was 88 \% against clinical rotavirus diarrhoea and 70 \% against all diarrhoea in the winter season. It is concluded that a single successful oral vaccination with RIT 4237 strain of bovine rotavirus protects children against rotavirus diarrhoea over an epidemic season. Studies are in progress to establish the duration of protection and possible enhancement of efficacy by vaccination with two doses. tributable to the vaccine were observed. There were 2 
It has been previously reported that ARG has an anti-absorptive ef fect when perfused in the man jejunum. To further investigate this action, we have looked at the effects of ARG on intestinal transport of water,electrolytes and glucose in the rat jejunum in vivo and on $\mathrm{Na}$ and $\mathrm{Cl}$ transpor.t in rabbit ileum in vitro. Results:perfu sion of ARGin rat jejunum results in a dose-dependent decrease of water and $\mathrm{Na}$ absorption; such effect starts at 50 uMol ARG and is already maximal at .5 mM. No effect is seen under such circumstances on glucose absorption. The specificity of ARG is stressed by the lack of effect on water and Na transport by the cationic amino aci d L-Lysine and by the dipeptide L-Tyr-L-Arg, both at $10 \mathrm{mM}$. When ad ded to the mucosal side of rabbit ileum mounted in Ussing Chambers $10 \mathrm{mM}$ ARG induced a powerful secretory change in both $\mathrm{Na}(-4.12 \pm 2.32$ $\mathrm{uEq} / \mathrm{cm}^{2} \cdot \mathrm{hr}$ ) and $\mathrm{Cl}\left(-4.92 \pm 1.62 \mathrm{uEq} / \mathrm{cm}^{2} \cdot \mathrm{hr}\right)$ transport, while having no effect when present on serosal side only. Conclusions: $A R G$, only when present on the luminal side, has a marked anti-absorptive effect on intestinal water and electrolyte transport. This effect is specific for free ARG and starts at a very low concentration, lower than tho se reported after a protein meal. Thus, oral administration of amino acid solutions containing free ARG should be avoided.

\section{2 ACUTE DIARRHOEA. E.Isolauri and T.Vesikari. Dept. Paediatrics, Tampere University Central Hospital,
Tampere, Finland}

COMBINATION OF ORAL REHYDRATION AND RAPID FEEDING IN

Oral rehydration with the WHO solution (sodium $90 \mathrm{mmol} / \mathrm{l}$, ORS-WHO) and minimal interruption of feeding form the cornerstones of treatment of acute infantile diarrhoea in developing countries, but these principles have not been generally adopted for use in Europe. We compared in 81 children hospitalized for acute diarrhoea rehydration with ORS-WHO and traditional oral fluid replacement with a glucose-electrolyte solution (sodium $35 \mathrm{mmol} / 1$ ), each combined with rapid or gradual (over 5 days) return to full feedings for age.

Rehydration with ORS-WHO, but not the traditional fluid replacement therapy, led to weight gain and correction of initial metabolic acidosis after 6-10 hours. The children receiving ORSWHO had a significantly lower mean concentration of reducing substances in stools $(0.2+0.9 \%)$ than those receiving the traditional glucose-electrolyte soTution $(1.9+1.9 \%), p<0.001$. Rapid return to full feedings was associated with earlier cessation of diarrhoea $(2.2+1.1$ days $)$ than gradual feeding $(3.4+1.8$ days $), p<0.10$. Of the four combinations of treatment, the ORS-WHO plus rapid feeding was associated with the best weight gain, shortest duration of diarrhoea and shortest hospital stay, and we recommend the application of these principles for treatment of acute infantile diarrhoea in industrialized countries.

\section{3}

DEVELOPMENT OF COLONIC TRANSPORT IN EARLY CHILDHOOD: IMPLICATIONS FOR DIARRHOEAL DISEASES IN INFANCY. P J Milla, A Heath. Institute of Child Health \& Hospital for Sick Children, London

Colonic reabsorptive processes are an important determinant of diarrhoea. In severe protracted diarrhoea in infancy (SPDI) we have previously suggested that the diarrhoea is due to overwhelming small intestinal secretion. Studies of colonic function in SPDI however are few and nothing is known of the development of colonic transport in the infant and the implication this holds for diarrhoeal diseases. We have used non-equilibrium dialysis of the rectum to measure electrolyte transport in controls and those with SPDI. There were 3 groups of controls, neonates(N) $0-1 / 12(n=8)$, infants $(I) 1 / 12-1 \mathrm{yr}(n=6)$, children(C) $1-4 \mathrm{yrs}(\mathrm{n}=8)$, and $\operatorname{SPDI}(n=9)$. In $C, \mathrm{Na}^{+}$was absorbed electrogenically and was less than $\mathrm{Cl}^{-}\left(\mathrm{Na}^{+} 211^{+} 7.8 \mathrm{SEM} \mathrm{nmol} / \mathrm{min} / \mathrm{cm}^{2} \mathrm{Cl}^{-} 225 \pm 9.8\right): \mathrm{HCO}_{3}^{-}$secretion accounted for the difference between $\mathrm{Na}^{+}$and $\mathrm{Cl}^{-}$. In $\mathrm{N}^{3}$ and $\mathrm{I}, \mathrm{Na}^{+}$ absorption ( $\mathrm{N} 115 \pm 9$, I $158 \pm 16$ ) was greater than $\mathrm{Cl}^{-}$( $\mathrm{N} 108 \pm 12$, I 127 \pm 13$)$ with reduction of $\mathrm{HCO}^{-}$secretion in $\mathrm{N}(\mathrm{N} 11.3 \pm 2$ vs I $33 \pm 10 \mathrm{p}<0.02)$. In SPDI $3 / 9$ had reduced $\mathrm{Na}^{+}$absorption( $87.6 \pm 8.2$ $p<0.02$ ) and potential difference (SPDI $3 / 913.2 \pm 2$ vs $34.4 \pm 5 \mathrm{mV}$ $\mathrm{p}<0.02)$ with reduced anion exchange ( $\mathrm{HCO}_{3}$ secretion $5 \pm 17$ vs $33 \pm-10$ $\mathrm{p}<0.02)$. In $3 / 9$ with SPDI impaired colonic function played a role in the production of the diarrhoea. In the neonate electrogenic $\mathrm{Na}^{+}$absorption and anion exchange is poorly developed but improves with increasing age. Thus the infant has reduced ability to conserve water and electrolytes and emphasises a susceptibility to dehydration from diarrhoea. of Medicine, Houston, Tx, USA and Departament of Pediatrics, University of São Paulo, Brasil.

The major fraction in feces $\triangle A^{-}$have never been completely identified in infantile diarriea. To assess fecal $\mathrm{OA}^{-}$in malabsorptive diarrhea, 12 infants with CSID, receiving glucose-containing formulas, were studied during 3-4 days. Daily fecal samples from $24 \mathrm{hr}$. collections have been analysed for osmolality and for total and individual $D A^{-}$measured by titration ( $T$ ) and by gas chromatography (GC), respectively. Undetermined anion (UA) was also daily estimated as the difference between fecal cations and anions. Mean concentration of short-chain fatty acids (SCFA) showed in $\mathrm{mEq} / \mathrm{kg}$ of stool: acetate 18, propionate 11, n-butyrate 5, isobutyrate 1.3, valerate 1, isovalerate 1.4. Mean concentration (mEq/kg) of lactate was 9, pyruvate 1.7. succinate 16 and citrate 2. From total $\triangle A^{-}$, only $17 \%$ accounted for SCFA. This figure increased to $44 \%$ when lactate, pyruvate, succinate and citrate were added and to $73 \%$ when long-chain fatty acids were taken in

account. $\mathrm{OA}^{-}$determined by 3 different methods correlated significantly with osmolality ( $p<.01)$. Good correlation between $\triangle A^{-}$by $T$ and $U A$ was shown $(r=.91)$. Conclusion: changes of $\mathrm{DA}^{-}$alter correspondingly the concentration in osmolalities and UA may represent a close approach for estimation of $\mathrm{DA}^{-}$component in feces.

ROLE OF INTRALUMINAL BILIRUBIN(BIL) IN THE PATHOGENE SIS OF DIARRHEA IN JAUNDICED NEWBORNS IN PHOTOTHERAPY. $\bar{A}$. M.De Curtis*,F.F.Rubaltelli**,A.Rubino.Inst.Ped.2nd Sch.Med.Univ. Naples. ${ }^{\star}$ Neonatol.2nd Sch.Med.Univ.Naples, Italy. **Ped.Clin.Univ. Padova, Italy.

Hyperbilirubinemic newborns in phototherapy of ten develop diarrhea presumably of the secretory type(1). Since free BIL is found in in creased amounts in the proximal small intestine of jaundiced Gunn rats undergoing phototherapy(2), we wished to verify the potential role of free BIL as secretagogue. Wistar rats were thus perfused into proximal jejunum with a modified Ringer solution(control period)and with the same solution containing different concentrations of BIL in the range of .2 to $1 \mathrm{mM}$ (test period)Results :BIL induced a dose-dependent inhibition of water, $\mathrm{Na}$ and $\mathrm{Cl}$ absorption with a half-maximal effect at .25mM.At 0.5mM,BIL was without effect on CAMP and CGMP concentrations.Also, no effect of 0.25 and 1 $\mathrm{mM}$ BIL on glucose influx in the in vitro rat jejunum was seen. In conclusion: intraluminal free BIL has a secretory effect, whose me chanism remains to be elucidated and may thus be responsible for the secretory diarrhea of jaundiced newborns in phototherapy. 1) De Curtis M. et. al.,Lancet, I:909(1982). 2)0strow J.D., J.C1 in. Invest., 50:707(1971).

\section{6}

THE DEVELOPMENT OF INTESTINAL DISACCHARIDASE ACTIVITY IN THE PRETERM INFANT. A.J. Mayne, D. Sule, Institute of Child Health, Univ. of Birmingham, UK. Foetal data suggest that intestinal lactase activity is low before 32 weeks gestation. We have shown in children that the disaccharidase activity in jejunal fluid correlates $(p<0.001$ ) with the enzyme activity in the mucosa. We have now measured disaccharidase activity in jejunal fluid from 8 preterm enterally fed infants of gestational age 26-29 weeks (mean 28 wks) on 17 occasions in the first 3 weeks of life. Postnatal developmental patterns were followed by longitudinal studies of the sucrase/ lactase $(S / L)$ ratio in 5 of these infants who were studied on $2-3$ occasions (mean 2.6) with an average of 6 days (range 3-8) between investigations.

Results: 5 infants were first studied within 18 hours to 6 days of birth. Mean lactase activity was $14.1 \pm 5.8 \mathrm{u} / 1$ ( $\bar{x} \pm$ SEM); all results were within the normal reference range $(6.3-35.0 \mathrm{u} / 1)$ for older infants. Longitudinal data showed a significant fall in the $S / L$ ratio from $3.3 \pm 0.6$ (range $2.0-4.5$ ) in the first week of life to $1.4 \pm 0.2$ (range $0.5-1.99$ ) in the 2nd and $3 \mathrm{rd}$ weeks of life.

Conclusion: Within the first week of life, preterm enterally fed infants have intestinal lactase activity within the normal reference range for older infants. There is a further rise in activity in the 2nd and 3 rd weeks of life, as reflected by a fall in $\mathrm{S} / \mathrm{L}$ ratio. 
HUMAN FETAL INTESTINAL SUCRASE-ISOMALTASE COMPLEX ALONG THE GESTATION. N. Triadou. INSERM U12, Unité de Recherches de Génétique Médicale, Paris, France.

Sucrase-isomaltase complex is expressed in human fetal small intestine from 10 weaks until term and in the large intestine between 12 and 30 weeks. The molecular form of the enzyme is studied by the immunoblotting methodology. Before 30 weeks the enzyme is present only as the high molecular weight form prosucrase-isomaltase while from 30 weeks until birth the two subunits are also present. However the fetal enzyme as its proform and as its two subunits has a faster electrophoretic mobility in SDS-polyacrylamide ael than the adult enzyme. The colonic and small intestinal foetal enzyme are identical. The maturation of the proform into its two subunits occurs at the time of enterokinase maturation, which allows pancreatic proteases activation, and these proteases are responsible of the cleavage of the proenzyme. The differences between adult and fetal enzyme may be due to differences in glycosylation or in amino acids sequence. Preliminary studies of the glycosylated portion of the enzymes will be presented.

SUCRASE-ISOMALTASE DEFICIENCY: A DEFECT IN INTRACEL LULAR PROCESSING OF THE ENZYME. M.J. Lentze, E.B. 18 Sterchi, H.P. Hauri, J. Roth and H. Gaze. University and University of Basle, Biocenter, 4065 Basle, Switzerland.

The intracellular localisation of sucrase-isomaltase $(S-I)$ was studied in ultra-thin sections of Lowicryl-embedded small intestinal biopsies from normal subjects and from a $31 / 2$ year-old girl with S-I deficiency. A monoclonal antibody against S-I was obtained by standard hybridoma techniques using purified human intestinal brush-border membranes (BBM) as the antigen. This antibody was specific for the isomaltase subunit as shown by immunoprecipitation and immunoblotting; it also recognized Pro-S-I. The enzyme was visualized by EM using anti-mouse IgG-antibody labelled with Protein A-Gold.

In normals extensive labelling was observed in the BBM with additional labelling in dense bodies (transport vesicles), in the Golgi (cis and trans) and in the endoplasmic reticulum (ER). In contrast, enterocytes from the S-I deficient patient showed no labelling of the BBM or of dense bodies, Labelling was restricted to the ER, to ER-vesicles on the trans-side of the Golgi and the Golgi itself. Compared to normal enterocytes there was a significant enrichment of label in the trans-region of the Golgi. Conclusion: although synthesis of the protein occurs in S-I deficiency a structural defect prevents it from being translocated to the brush-border membrane.

(Supported by SNF 3.961.0-81)

ABNORMAL BRUSH BORDER MYOSIN BINDING IN CONGENITAL VTCROVILITS ATROPHY

L Carruthers, A D Phillips, R Dourmashkin and
J A Walker-Smith. Paediatric Gastroenterology
Laboratory, St Bartholomew's Hospital and Queen
Elizabeth Hospital for Children, London, Fngland.

Brush border membrane proteins of the small intestinal mucosa from a child with congenital microvillus atrophy were compared with those from normal $(n=7)$ and diseased intestinal tissue $(n=19)$. The membrane proteins were extracted from biopsies and surgical specimens of both small $(n=14)$ and large intestine $(n=12)$. Pure brush borders, as judged by electron microscopy, were analysed by polyacrylamide gel electrophoresis. Despite a wide age range in the patients studied, a prominent protein band with an apparent molecular weight of $200 \mathrm{~K}$ was consistently present in all specimens from both small and large intestine except from the child with congenital microvillus atrophy. Here analysis showed a striking diminution of the $200 \mathrm{~K}$ band. This band ran parallel to characterised myosin, as used in the molecular weight standards. Nyosin is known to be a prominent protein in the plasma membrane. These results suggest a failure of myosin to bind to the terminal web in the brush border membrane, thereby leading to a perturbation of the membrane's cytoskeleton resulting in ultrastructural abnormalities of the microvilli characteristic of this disorder, namely involution of the microvilli.
DUODENAL MANOMETRY IN POST OBSTRUCTIVE ENTEROPATHY,

Intestinal motility was studied in 9 children with post obstructive enteropathy and transient enterostomy ( 5 total colon Hirschsprung diseases, 3 enterocolitis with stenosis, 1 intussusception). 3 groups of decreasing severity were determined clinicaly: duration of Parenteral Nutrition (PN) and Constant Rate Enteral Nutrition (CREN), septicemia originated from the gut and oral feeding tolerance. Intestinal motility study inclued: transit time with an inert marker, baryum small intestine transit, and duodenal manometry coupled with electromyography. Inert marker transit time and baryum transit show no correlation with clinical groups except group I. In contrast, manometric abnormalities, especially phase 111 , were well correlated with clinical classification.

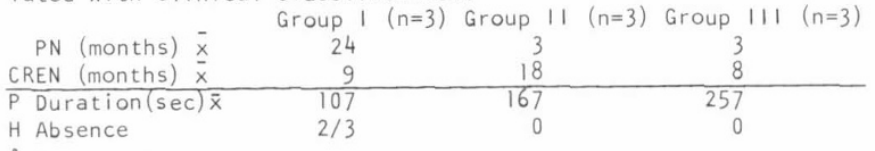

A propagation

E Abnormalities

$1 / 3$

11I This study suggest that the main mecanism of this enteropathy is a chronic motility alteration induced by prolonged or repetitive obstruction.
PEPTIC ULCER IN CHILDHOOD - HOW MANY DO WE MISS? 21 E.J.Eastham, M.Z.Jiminez, R.H.Jackson, R. Nelson Dept. of Child Health, Royal Victoria Infirmary, Newcastle upon Tyne, England.

The prevalence of peptic ulcer disease in childhood is incertain. Recurrent abdominal pain is common (10\%), and it is well known that peptic ulcer disease does not conform to standard adult symptomatology. The wide variation in prevalence of ulcer disease in different centres possibly reflects the criteria for which investigations are instigated. Other than haematemesis and melaena, we regard nocturnal pain and/or a positive family history as an indication for endoscopy. Using these criteria, analysis of 173 consecutive patients undergoing endoscopy reveals 39 peptic ulcers $(22.5 \%$ ) mean age 12 years (range $4-16$ years). The male: female ratio was $3: 1$. There were 31 primary duodenal ulcers, 2 secondary, 3 pre-pyloric and 3 gastric ulcers. $80 \%$ had a positive family history and $90 \%$ had nocturnal pain. More than one ulcer was found in $15 \%$, associated duodenal deformity in $70 \%$ and duodenitis in $50 \%$.

Compared with other European centres, our prevalence of duodenal ulceration in childhood is high. Unless peculiar regional factors prevail, we feel that underdiagnosis of this condition may be considerably and suggest that any child presenting with recurrent abdominal pain, in whom there is a positive immediate family history or the presence of nocturnal pain, should be subjected to upper gastrointestinal endoscopy.
THE PSYCHOSOCIAL ADJUSTMENT OF CHILDREN AND ADOLESCENTS FOLLOWING STOMA SURGERY FOR INFLAMMATORY BOWEL DISEASE (IBD). I Booth, B Lask, J Jenkins, L Nabarro, J Harries. Hospital for Sick Children \& Institute of Child Health, London

The psychological sequelae associated with stoma surgery in childhood and adolescence have not been previously investigated. However, the notion that their severity in young patients could be unduly handicapping, may lead to inappropriate deferment of surgery. Comprehensive psychiatric and psychometric assessments were therefore performed in 3 groups of patients:i) 12 patients who had had stoma surgery for IBD before 16;ii) a matched group with IBD but no stoma;iii) 8 patients with IBD and an ileorectal anastomosis.

No significant difference existed in scores for overall adjustment, self-image or quality of life between groups, or between any group and published control scores. Of a number of independent variables, such as age at onset and at surgery, and degree of education about the disease, none was a significant predictor of the quality of subsequent adjustment.

Thus, following stoma surgery, there does not appear to be an increased incidence of emotional and behavioural problems, social isolation, sexual difficulties or psychosomatic symptoms. These findings may therefore have important implications for the timing of stoma surgery in children and adolescents with severe IBD, which should not be deferred because of feared psychological sequelae. 
LONG-TERM FOLLOW-UP OF YOUNG PATIENTS WITH RECTAL MUCOSECTOMY AND ILEO-ANAL ANASTOMOSIS (RMIAA). Jean Perrault, Robert Telander (Spon. by Peter Milla). Mayo Clinic and Mayo Foundation, Department of

Pediatrics and Pediatric Surgery, Rochester, MN U.S.A.

RMIAA is more widely used after colectomy for chronic ulcerative colitis (CUC) or familial polyposis (FP). 30 patients have been followed prospectively for $>12$ months after RMIAA with straing pull-through by sending a detailed questionnaire every 6 months and yearly visits. Stool frequency and character follow:

\begin{tabular}{ccccc} 
Months post-op & 12 & 24 & 36 & 48 \\
\hline f of patients & 305 & 1910 & 204 & 1010 \\
Age: yrs-mos & $19^{5}$ & 18 & $19^{4}$ & 19 \\
(Range) & $\left(12^{6-315)}\right.$ & $\left(13^{10-257)}\right.$ & $\left(145-27^{3}\right)$ & $(153-249)$ \\
\# of Stools-Day & $6.2(0-10)$ & $6.0(0-18)$ & $5.0(2-9)$ & $4.6(2-7)$ \\
(Range) - Night & $2.1(0-4)$ & $2.8(0-9)$ & $1.9(0-4)$ & $2.1(0-6)$ \\
Liquid/formed stools & $3 / 19^{x}$ & $3 / 24^{x}$ & $3 / 22^{x}$ & $1 / 10^{x}$ \\
\hline
\end{tabular}

All patients learned to discriminate stool from flatus and many did not use medications ( $6 / 19$ at 12 mos, $4 / 10$ at 48 mos). Gross incontinence and perinal irritation were unusual ( 2 pts) yr). CBC, liver function tests, Vitamin BI2 and stool fat were normal when checked. All patients were satisfied $(50 \%$ very satisfied) at 48 mos ( 2 pts. not satisfied at 12 mos). Conclusion: RMIAA is well tolerated clinically and psychologically by young patients and permits stool elimination closer to normal. The frequency of stooling decreases gradually with time. $\times$ Some patients gave more than 1 qualification.
Vitamin $\mathrm{A}$ and $\mathrm{E}$ nutrition may be impaired by steatorrhoea in preterm infants, but the extent to which this occurs in very low birth weight infants has not been fully evaluated. We therefore measured plasma concentrations of these vitamins by HPLC in 31 such infants ( $\mathrm{BW} 1099 \pm 283 \mathrm{~g}$, gestation $28 \pm 1.8 \mathrm{wk}$ ) at 28 postnatal days, at the same time as a 3 day fecal fat estimation. The infants were fed on breast milk (11), formula (11) or a mixture of both (9). Supplementary vit A (4000 IU/day) was given, but no supplementary vit $E$, and daily intakes were calculated. Fecal fat varied between 1.4 and $7.6 \mathrm{~g} / 24 \mathrm{hr}$., but no correlation was found between fat excretion and plasma vitamin levels. There was no relationship between dietary intake of vit $A$ and $E$ and plasma concentrations, nor was there any difference relating to type of feeding. However concentrations of vit $A$ and $E$ were significantly correlated with each other $(r=+0.66, p<0.001)$.

Circulating concentrations of these vitamins reflect storage and utilization rather than dietary intake, but their interrelationship suggests a metabolic interaction. Perhaps vit E protects vit A from oxidation.

\section{COLOSTRUM. B.L. Nichols and K. McKee USDA/ARS 27 Children's Nutrition Research Center, Department of Pediatrics, Baylor College of Medicine, Houston, TX,
USA. (Sponsored by J.K. Visakorpi)}

Animal experiments have demonstrated increased weight and DNA in the mucosa of maternally-nursed young animals compared with those who were fed artificially. An in vitro assay was developed for measuring ${ }^{3} \mathrm{H}$-thymidine incorporation into DNA which utilizes the crypt cells harvested from mature rat jejunum by the method of eversion and vibration. These cells were incubated in Trowells-T8 medium in the presence of 10\% fetal calf serum. The addition of $5 \%$ human colostrum to these incubated crypt cells resulted in a $22 \pm 14 \%$ increase in thymidine uptake into DNA at 30 and 60 minutes. Addition of epidemal growth factor at the concentrations found in human colostrum neither increased thymidine uptake nor altered the increased incorporation due to colostrum. These findings are inconsistent with previous demonstrations that epidermal growth factor stimulates enterocyte proliferation in vivo, but are consistent with the previously suggested presence of other colostral factors which stimulate cell division. This is the first in vitro proof that other enterocyte mitogenic factors are present in human colostrum.

\section{AND ARTIFICIALLY FED INFANTS UP TO 6 MONTHS OF AGE. BE Ginsburg, BS Lindblad, A Lundsjö, B Persson, $R$ Zetterström Dept. Paediatrics, Karolinska Institute, \\ St. Göran's Children's Hospital, Stockholm, Sweden.}

Plasma branched chain amino acids and urinary $C$-peptide-creatinine excretion was determined at $3,4 \frac{1}{2}$ and 6 months of age in a group of 50 patients who were either breast-fed or artificially fed and selected at random.

The average concentration of valine in plasma and $\mathrm{C}$-peptide in urine as well as the ratio between $c$-peptide and creatinine in urine were $2-3$ times higher $(p<0.01)$ in artificially fed (protein intake $2.0 \mathrm{~g}$ protein per $100 \mathrm{kcal}$ ) as compared to breast-fed infants at al1 the ages studied. The same difference between breast fed and artificially fed infants was also observed in infants of 6-8 weeks of age. In infants of an age between 3 and 5 months weaning was followed by an immediate increase in the plasma concentration of valine as well as in the urinary excretion of $c$-peptide. Plasma valine values correlated significantly with the urinary $C$-peptide/creatinine ratio $(r=0.76, p<0.01)$, which suggests that the enhanced insulin response induced by the artificial formula is related to its protein content.

Studies on infants of 6,10 and 18 months of age are now in progress to elucidate if the relation between protein intake and plasma valine levels is transitory or persisting.
ENTERAL FEEDS AND INTESTINAL MOTOR ACTIVITY IN THE PRETERM NEONATE. E Wozniak, T R Fenton, P J Milla.

28 Institute of Child Health and Hospital for Sick

28 Institute of Child Health and Hospital for Sick Provision of adequate nutrition is a major problem in the preter be related to immaturity of intestinal motor activity.

Using constantly perfused rasojejunal catheters we have studied fasting and fed small intestinal motor activity longitudinally in 8 neonates born between 26 and 30 weeks gestation. Three patterns of activity associated with gestational maturity were seen: 1) 26-30 wks disorganised random contractions, 2) 30-33 wks frequently recurring short bursts of regular contractions propagated aborally, 3) 33-36 wks cycles of propagated rhythmic 11 cycle/minute activity resembling migrating motor complexes (MMC). It was striking that change to this latter pattern of activity was associated with the onset of the ability to suck. Food did not appear to modify these patterns of fasting activity. In 3 term babies well established cyclical fasting activity with MMC's similar to those seen in older children occurred.

The onset of sucking coincident with the appearance of the MMC-like pattern suggests that the development of intestinal motility is closely related to neurological maturation. The disorganised nature of activity in stage 1 may account for intolerance of enteral feeding. 
Dysfunction of UES motility was found in 4 out of 32 children with GER and esophagitis (M: 2; F: 2; mean age: 12.5 months). Three of the 4 showed mental retardation and were affected by Silver Rus sell syndrome, 5p-syndrome and benign congenital myopathy, respectively. All the four children complained of swallowing disorders and vomiting; 3 showed failure to thrive, severe pulmonary aspiration and incompetent lower esophageal sphincter. In 2 children UES relaxation was incomplete, in the other 2 it was not coordinated with pharyngeal contraction. Cure of GER and esophagitis by domperidone did not improve swallowing disorders or symptoms of pulmonary aspiration. A fifth patient with myopathy and mental retardation, referred for anorexia and failure to thrive, showed complete esophageal aperistalsis. This study suggests that: 1)a primary dysfunction of UES motility may play a role in the swallowing disorders and respiratory symptoms in children with GER; 2) UES and esophageal dysfunction may be a part of a more generalized nervous or muscular disorder.

${ }^{\circ}$ E.Mancini, ${ }^{\star M}$.Minett $i,{ }^{\circ} 0$. Sapora, ${ }^{\circ} \mathrm{V}$. Silano. ${ }^{\circ}$ Dept. of $\mathrm{Cl}$ inical

Paediatrics, II Fac. of Medicine, University of Naples, Naples;

-Dept. of Comparative Toxicology and Ecotoxicology and *Dept. of Cell Biology, Istituto Superiore di Sanità, Rome, Italy.

We have demonstrated that the lectin-like activity of prolamin peptides from cereals toxic for coeliac patients is inhibited by $\mathrm{N}$-acetylglucosamine, mannose and mannan (Auricchio S. et al.,Ped. Res., in press). Peptic-tryptic-pancreatic gp prevented the recovery of enterocytes which occurred when atrophic mucosa of coe-

liacs is cultured in the absence of toxic peptides. Mannan alloENTEROCYTE HEIGHT (mean \pm SD)

\begin{tabular}{|l|c|c|c|}
\hline Uncul- & \multicolumn{3}{|c|}{ After $48 \mathrm{~h}$ culture } \\
\cline { 2 - 4 } tured & $\begin{array}{c}\text { Without } \\
\text { gp }\end{array}$ & \multicolumn{2}{|c|}{ With gp $(0.5 \mathrm{mg} / \mathrm{ml})$} \\
\cline { 3 - 4 } & & alone & $\begin{array}{l}\text { tmannan } \\
\end{array}$ \\
17.62 & $20.54^{\circ}$ & 17.50 & $(5 \mathrm{mg} / \mathrm{ml})$ \\
\pm 0.70 & \pm 1.97 & \pm 0.66 & \pm 1.48 \\
$(n=14)$ & $(n=4)$ & $(n=10)$ & $(n=14)$ \\
\hline
\end{tabular}
wed a significant improvement of coeliac mucosa cultured with gp. Mannan also partially prevented the difference from uncultured mucosa $p<0.01$ tal rat intestine.Mannanis therefore able to detoxify gp in these in vitro models of
coeliac disease.

OESOPHAGITIS AND GASTRO-OESOPHAGEAL REFLUX DURING SLEEP IN CHILDREN WITH REPEATED LOWER RESPIRATORY TRACT SYMPTOMS. M. Baer, M. Mäki, T. Vesikari, V. Turjanmaa, J. Nurminen, J.K. Visakorpi. Department of Paediatrics, University Central Hospital of Tampere, Tampere, Finland.

Gastro-oesophagoscopy was performed on 117 children (mean age $7.9 \pm 3.5$ years) with recurrent lower respiratory tract symptoms to search for clinically significant gastro-oesophageal reflux (GER). Oesophagitis was verified in 52 (45\%) patients. 5 patients had severe ulcerative and 21 had moderate oesophagitis; in 25 patients the diagnosis was based on histological examination of biopsies of endoscopically normal (9) or mildly inflammated oesophagus (16). Duodeno-gastric reflux (bile-stained gastric content) was found in 14 of 35 patients with oesophagitis and in 1 of 31 patients without oesophagitis $(p<0.001)$. Only 1 of the patients with oesophagitis had hematemesis and anemia and $59 \%$ had had no abdominal symptoms. Oesophageal pH recordings for 18-24 hours revealed significant GER during sleep in $21 / 22$ (95\%) children with oesophagitis as compared to $8 / 19$ (42\%) with no oesophagitis $(p<0.001)$. The percentage of oesophageal clearance time was also significantly higher in children with oesophagitis than in those without $(p<0.01)$. Treatment of GER led in most cases to amelioration or cure of both oesophagitis and respiratory symptoms.

LECTIN-LIKE ACTIVITY OF CEREAL PROLAMIN-DERIVED PEPTI31 DES:IMPLICATIONS FOR THE PATHOGENESIS OF COELIAC DISEA

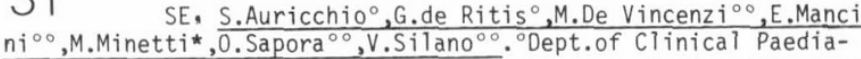
trics, II Fac. of Medicine,University of Naples, Naples; ${ }^{\circ}$ Dept of Comparative Toxicology and Ecotoxicology and *Dept.of Cell Biology, Istituto Superiore di Sanità, Rome, Italy.

It has been suggested that cereal peptides may damage the coeliac intestinal mucosa by a cytotoxic action on immature or immature-like enterocytes (Auricchio S.et al.Ped.Res.In press).Peptic tryptic peptides (PTP) of prolamin from bread wheats, rye, barley and oats and of bread wheat A-gliadin (gift of Dr.D.Kasarda) were very active in agglutinating undifferentiated in vitro cultured K $562 \mathrm{~S}$ cells (Lozzio C.B.et al.Blood $45: 321,1975$ ). The minimal concentrations required to agglutinate $30 \%$ of total cells (MAC) were: $3.2 \mathrm{mg} / 1$ of PTP of wheat gliadins, $0.3 \mathrm{mg} / 1$ of PTP of A-gliadin, $4 \mathrm{mg} / 1$ of concanavalin $A$ and $20 \mathrm{mg} / 1$ of wheat germ agglutinin. The MAC of PTP of wheat gliadins was much higher $(412 \mathrm{mg} / 1)$ when tested on erythroid differentiated K $562 \mathrm{~S}$ cells. The agglutinating activity was inhibited by $\mathrm{N}$-acetylglucosamine, mannose and mannan and was reversed by mannan.PTP of rice and maize prolamins did not agglutinate undifferentiated $\mathrm{K} 562 \mathrm{~S}$ cells. There is there fore a good correlation between toxicity for coeliacs of cereal prolamins and their lectin-like activity on undifferentiated cells.
GLUTEN IN HLA-IDENTICAL AND NON-IDENTICAL SIBLINGS

33 OF CHILDREN WITH COELIAC DISEASE, I. Polanco, M.L.Mearin, J.Larrauri, A.S.Pena, C.Vazquez. Gastroent. Unit, Dep. of Pathology, "La Paz", Madrid, Spain and Dept. of Gastroent. Leiden, The Netherlands.

Genetic and environmental factors are implicated in the pathogenesis of coeliac disease (CD). We have studied the effect of giving $18 \mathrm{gr}$ of additional gluten per day in a normal diet during a four week period to healthy siblings (mean age: 10 yrs) of coeliac children. Five children were HLA-DR identical, four shared one of the HLA-DR antigens and two had completely different HLA-DR antigens to their respective CD sibling. Clinical and functional studies consisting of routine blood and Xylose test were performed before, during and after challenge. A jejunal biopsy was obtained at the end of four weeks. Gluten was given in biscuit form( $3 \mathrm{~g}$.each) prepared for us by LIGA Netherlands. The present study was approved by the Ethical Committee. No clinical abnormalities were found during the period of study. In three cases a slight byt not significant decrease in Xylose absorption occurred. No histopathological abnormalities were seen in any of the jejunal biopsy specimens at the end of the challenge. The present study does not support the concept that gluten alone is toxic, in susceptible individuals who do not have overt coeliac disease and suggest that other factors than DR antigens and gluten are also important in disease expression.

1) Doherty M. and Barry RE. Lancet, i,517,1981.

\section{IS THERE A "NATURAL RECOVER"? J. Schmitz, F. Arnaud- Battandier, J.Jos, J. Rey. Department of Paediatrics Hôpital des Enfants Malades, PARIS, FRANCE. \\ The long term evolution of $\mathrm{CD}$ in children left with a normal} diet (n.d.) is poorly known and the possibility of a "natural recovery"(including an histological one) as the permanence of the jejunal mucosa sensitivity to gluten throughout life have never been established prospectively.

Since 1963-4 children with CD are put on a gluten-free diet for $2-3$ years, relapse being induced by returning to $n$.d. When relapse is only histological n.d. is maintained, the child being followed up with clinical examination every $6 \mathrm{~m}$ or $1 \mathrm{y}$, biological tests every $2-3$ y and a biopsy every 5 y. 34 children (23 \&, 11 of) aged every $2-3$ y and a biopsy every 5 y. 34 children $(23$ t' 11 teast one other biopsy. 81 biopsies were thus analyzed independantly by $\mathrm{FAB}$ and JS, lesions being classified from 1 (N) to 6 (TVA). 5 chil dren had an incomplete relapse (grades 2-3) and will not be considered further. In the 29 others lesions were severe (grades 4-6) at relapse. Later on lesions remained severe 15 times after 5 to $19 \mathrm{y}$ of $\mathrm{n}$.d., worsened 4 times, but clearly recovered totaly (4) or partialy (6) 10 times after 5 to 13 y of $\mathrm{n}$.d. $\left(2 f^{\prime \prime}\right.$ and $8 \mathrm{f}$ among whom are included 3 already published).

The sensitivity of the intestinal mucosa to gluten thus decreases in the long term in a subgroup of coeliac children. This finding challenges the concept of the permanence of $C D$ or of its homogeneity according to the Interlaken criteria. 
PARENTS' UNDERSTANDING OF COEL IAC DISEASE(CD) AND ITS DIETARY MANAGEMENT. PT Jackson, JFT Glasgow, R. Thom.

Dept. Child Health, The Queen's University of Belfast

For the past 12 years CD has been diagnosed on the basis of a flat jejunal biopsy and a good clinical response to strict gluten withdrawal(GFD). In 8 cases in whom dietary adherance was questioned an additional compliance biopsy(CB) had been subsequently required. In the present study a standard questionnaire was given to parents of 50 children with CB, current age 1.5-19.0yr, and responses

scored to give quantitative data about understanding of $C D$, knowledge of the GFD and likely adherance. 27 knew that the GI tract is primarily involved, 30 that $C D$ is lifelong, 41 that gluten is to be avoided and $>70 \%$ knew which of 14 common foods contained gluten. Although $1 / 3$ considered it an'easy'diet to keep, in $40 \%$ adherance was less than strict. $8 / 33$ parents with a knowledge score(KS) of $<4$ had a child who had previously required $C B$, compared to $0 / 17$ with a $K S$ of $5-8(P=0.07) .6 / 8$ requiring $C B$, thought the diet'easy', compared to $10 / 42$ not requiring $C B(P<0.015)$. There was no relationship between the need for $C B$ and the number of parents at home or parental trust in the child's compliance. KS was positively correlated with-social status score $(P<0.0006)$, dietary adherance $(P<0.0001)$ and the possession of a recent $i$ ist of gluten free products $(P<0.028)$. Conclusions: $2 / 5$ CD cases do not adher to a strict GFD and in 16\% there had previously been a serious problem of compliance. Parents' perception of the diet and the child's ability to comply may be at variance. More emphasis should be placed upon regular dietetic advice.
SULFATED GLYCOLITHOCHOLIC ACID INDUCED CHOLESTASIS: 38 Netherlands. THE ROLE OF THE ENTEROHEPATIC CIRCULATION (EHC) Sulfated glycolithocholic acid (SGLC) causes cholestasis in rats. However, little is known about the underlying mechanism and factors involved in protection. In the present study this was investigated in rats in which the circulating bile acid pool had been exhausted by interruption of the EHC and compared with the effects in rats with an intact EHC. The rats were equipped with permanent catheters in the bile duct, the duodenum and the heart.

Intravenous administration of SGLC ( $8 \mu \mathrm{mol} / 100 \mathrm{~g}$ body weight) to rats with an intact EHC did not result in significant changes in bile flow and biliary lipid composition when compared with control rats. When the same dose of SGLC was injected in rats after 24 hours of biliary drainage, a complete but reversible cessation of bile flow was observed within 45 minutes. In the recovery phase biliary bile acid concentration was increased with 50 to $80 \%$. In contrast, biliary phospholipid concentration was strongly reduced. Both parameters normalized thereafter.

In conclusion: the hepatotoxic effect of SGLC is much more pronounced in rats with an exhausted bile acid pool. This phenomenon may have clinical implications for patients with a contracted bile acid pool.

Supported by a grant from HGO-TNO (13-53-44).
THE EPIDEMIOLOGY OF REYE'S SYNDROME IN THE BRITISH ISLES. S.Hall, M.Bellman, Communicable Disease Surveillance Centre, London, England

\section{Ku lesza T. Zalowsk Dept.CIIn.BIocher.,Pediat.CIIn.Med.Acad.War saw, Child Health Center, Wareaw, Poland}

The aim of the study was the verification of elinical usefulness of messurement of intest.clerance of a At. The determinations of a At were performed on marked, timed 3-days collectlond of peces /according to Bernier J. ot al., Iancet II,763,1978/ using 1 or IC" Part1gan" Behringwerke.

Control group comprised 5 chlldren, in the age of $9 / 12$ to 7 years: $\bar{x}-2,52 \mathrm{ml} / \mathrm{day}$, range 0,7 to $3,8 \mathrm{ml} / \mathrm{day}$.

Patients:3 cases of protein loosing enteropathy /PLE/1.Girl, 14 years, threofold determinations; $15,8 \mathrm{ml} / \mathrm{d}$, $18,6 \mathrm{ml} / \mathrm{d}$, and in exacerbet1 on 198,4 ml/d; 2.G1rl,9/12 $65,2 \mathrm{ml} / \mathrm{d} ; 3$. G1rl, 3,5 years, $236,0 \mathrm{ml} / \mathrm{d}$.

Other cases: 1.0esophag1t1s, Morb.Barret, 6 years,10,4 and $14,3 \mathrm{ml} / \mathrm{d}$. 2.D1arrhoos rec1div. 8 yoars, $19,1 \mathrm{ml} / \mathrm{d}$. 3. Morb.G1lbert, 14 years, $11,3 \mathrm{ml} / \mathrm{d}$. 4.Cyot1c fibr. 2 years, 7,0 ml/d. 5. Pericardit. constr. Insuf. cordis dext. 18 years, $800 \mathrm{ml} / \mathrm{d} / 1 /$. Foces contaminated with blood. There wae a good correlation between dally excretion of At and Inteatinal clearance $/ x=0,99 /$.

The determination of intest.clearance of a At oubstant1ates in a convenient, non aggresive way, the diagno1s of PLE, Indicates the involvement of GI-tract into the pathological processes in extre GI-tract diseses.

Hepatitis Syndrome in Infancy: An epidemiological 37 study $(1971-73)$ with 10-year follow up.

G Mieli-Vergani, M Dick \& A P Mowat. Dept.Child Health King's College Hospital. London SE5

In a prospective study 54 infants with conjugated hyperbilirubinemia of more than 2 weeks duration, and abnormal biochemical tests of liver function (LFT) were identified in 16 general paediatric units in a circumscribed area in SE England. To determine the prognosis to loyrs of age, regular clinical and LFT assessment has been performed.

10 of 11 with billary atresia died from liver disease as did 5 of 7 with alpha-1 antitrypsin deficiency. The survivors have chronic liver disease. One child with Trisomy 13 died, as did 3 of 4 with "intrauterine" infection. The survivors of this group and 4 other children with miscellaneous causes are currently well. 2 of 28 with idiopathic disease died in the first year of life but in the survivors liver disease has pradually subsided. Jaundice cleared in all by 26 wke of age. Hepatosplenomegaly was present in 14 at $1 \mathrm{yr}, 4$ at $3 y r s$ and 2 at 10yrs. LFT's were abnormal in 13 at $1 \mathrm{yr}$, 3 at $3 y r s$ and none at 10yrs. 3 attend ESN schools.

This study, in contrast to studies from referral centres, emphasises the generally good propnosis of idiopathic hepatitis compared with other forms of hepatobiliary disease in infancy.

\section{9}

The objectives of this study are to: 1) describe the characteristics of Reye's Syndrome (RS) in the British Isles and monitor long-term trends; 2) provide a central case register and bank of pathological material for clinical or laboratory research. Methods. The study is run jointly with the British Paediatric Association. In August 1981 all consultant paediatricians in the British Isles were provided with RS report forms. They were subsequently asked to supply detailed epidemiological and clinical information on a standard questionnaire for each reported case. Results of the first two years' surveillance: 87 patients ( 30 in the first year, 57 in the second) were reported; $63 \%$ were under 2 years of age; there was no clear winter peak or rural predilection (both previously described in the USA); a variety of prodromal viral infections were identified, including 4 caused by echoviruses; less than half the patients were examined histologically; mortality was $56 \%$; 8 patients who met the clinical and biochemical case criteria for RS had their diagnoses revised later: 4 had inborn metabolic errors. Conclusions: RS has different epidemiological characteristics in Britain from that described in the USA. There is a need for more detailed biochemical and histological examination of children presenting with a RS-like disorder.

40

INTERIM RESUL TS SHOW MAJOR IMPROVEMENT IN SURVIVAL IN PRE-ICTERIC INDIAN CHILDHOOD CIRRHOSIS(ICC) TREATED WITH D-PENICILLAMINE(DMC). MS Tanner, DG Sidhaye, SA Bhave, AM Pradhan Dept Child Health, University of Leicester,UK and Dept Pediatrics, KEM Hospital, Poona, India

Untreated, $74 \%$ of children with ICC died within 8 weeks (1980). DMC in advanced cases insignificantly improved survival (1980-81), DMC $20 \mathrm{mg} / \mathrm{kg} /$ day (Group D), DMC + prednisolone $2 \mathrm{mg} / \mathrm{kg} /$ day for 4 weeks then $5 \mathrm{mg} / \mathrm{kg} /$ day (Group S), or placebo (Group P), was given to 24 cases of ICC without ascites or jaundice. 13 were allocated to groups in rotation (1982). 11 entered a double blind sequentially analysed study with code breaking after 3 months (1982).

Results to 1984: 8 out of 8 in Group P died after $41 \pm 31$ (12-109) days. 4 out of 8 in Group D and 3 out of 8 in Group S died after $132 \pm 148$ (35-448) days. 9 out of 16 in Groups D and S are well after 15.8 -6.4 (6-25)months. Analysis of entry parameters indicate a marginal Group $P$ disadvantage, preventing trial discontinuation. In biopsies of survivors after 6 months, 3 show inactive cirrhosis, 2 are normal. 

(LTX) in 17 children aged 11 months to 15 years were performed. These children suffered from extrahepatic biliary atresia $(n=7)$, end-stage liver cirrhosis $(n=7)$ and non-resectable liver malignoma $(n=3)$.

11 patients survived up to now, the follow-up covering 1 to 36 months. 6 patients show normal enzyme activities 5 have normal bile acid, 9 have normal bilirubin and 10 have normal LP-X concentration i.s. The quality of life is good to excellent in 9 children. The non-survivors died from septicemia $(n=3)$, recurrence of malignoma $(n=2)$ and graft failure $(n=2)$ after 1 week to 26 months of survival.

These results indicate as other reports (1) that LTX may offer a good change for children with otherwise fatal liverdisease.

(1) Malatack, JJ Transpl.Proc. XV, 1292 (1983)
From 1978 - 198318 orthotopic liver transplantations

DERMATITIS HERPETIFORMIS IN MONOZYGOUS TWINS: DISCORDANCE FOR DERMATITIS HERPETIFORMIS AND CONCORDANCE FOR GLUTEN SENSITIVE ENTEROPATHY I.Kosnai, S.Karpati ${ }^{3}$, E. Gyddi $^{4}$, P.Bucsky, E. Török ${ }^{3}$ First Dept. Of Paediatrics, 2nd ${ }^{3}$. Inst. Haemat. and Blood Univ. , Heim $\mathrm{Pdl}$ Children's Hosp.
Transfusion, Budapest, Hungary.

A monozygous female twin pair with childhood dermatitis herpetiformis(DH) is reported. Previously one concordant and a discordant twin pairs with adult DH were published.

Twin $A$ had skin rash from the age of 3 years. The diagnosis of $\mathrm{DH}$ was verified by demonstrating granular IgA deposits in the uninvolved skin at the age of 5 years. She had recurrent diarrhoea and height $-1.3 \mathrm{SD}$, weight $-2.3 \mathrm{SD}$. Twin $B$ had no gastrointestinal symptoms but height $-1.3 \mathrm{SD}$ and weight $-3.2 \mathrm{SD}$. She had neither skin symptoms nor granular IgA deposits at skin biopsy. Both had high fecal fat excretion and subtotal villous atrophy in the proximal jejunum at the age of 5 years. Gluten sensitive enteropathy was verified in both of them by serial biopsies according to the ESPGAN criteria.

Monozygozity was proved by the standard genetic characteristics.

This twin case provide some additional information to the genetics of DH.

MUCOSAL LYMPHOCYTES (ML) IN ALLOTRANSPLANTED SWINE SMALL INTESTINE (SI). F. Arnaud-Battandier, H. Salmon M. Vaiman, Y. Revillon, P. Gallix, M. Olivier, C. Ricour. HÔpital des Enfants Malades 75015 PARIS

\section{et INRA 78850 THIVERVAL-GRIGNON - FRANCE}

Using continuous treatment with Cyclosporine, swine were able to tolerate total SI allografts. However because of the large numbers of ML normally contained in the SI and their major role in the mucosal immune barrier, it was of importance to appreciate their functional value after transplantation. ML were isolated from segments of 3 SI grafted thore than 1 year before. By comparison with ML from normal animals no differences could be found in the distribution of Iymphocyte subctasses, the proliferation in presence of mitoyens, and the production of interfeukin 2. Studies by cytotoxicity of the major histocompatibility complex demonstrated that the ML from the graft were of the recipient phenotype with an important proportion of $\mathrm{Ia}(+)$ lymphocytes. In a preliminary experiment, using an allotransplanted Thiry-Vella loop and staining with fluorescein and rhodamine of the intestinal lymphocytes of the donor and mesenteric lymphocytes of the recipient respectively, it was observed a rapid migration of the donor lymphocytes and an early presence of the recipient lymphocytes in the grafted loop. Within one month donor lymphocytes could not be detected. In conclusion under Cyclosporine SI grafts were colonized by the lymphocytes of the recipient without detectable changes in their distribution and their functions.

SUSCEPTIBILITY FOR COELIAC DISEASE (CD) AND FOR JUVENILE DIABETES MELLITUS (JDM) CAN BE MAPED TO THE SAME HLA-DR3 POSITIVE HAPLOTYPE. E.ROSSipal, S.Scholz Ch. Brautbar, Rachel McKenna, E. Albert. Dept. of Paed. Univ. Graz, Austria; Laboratory of immungenetics, Dept. of Paed. Univ. Munich, West Germany; Hadassah Medical School, Jerusalem, Israel; Dept. Of Med. Regional Hospital, Galway, Ireland. Joint occurence and segregation of $C D$ and JDM in relationship to HLA was investigated in five families. Three patients suffering from CD and JDM had the genotypes A2 Bw60 DRw6/A2 Bw39 DR3, A1 B8 DK3/A1 B8 DR3 and A1 B8 (DR not typed)/A3 Bw35 (DR not typed). In the second family there is a very high probability that the A1 B8 DR3 haplotype is identical by descend.

In three families one ore more first degree relatives of the $C D$ index case are suffering from JDM. In the first family the DR3 positive haplotype of the $C D$ patient is different from the DR3 positive haplotype of the JDM patient. In the other two families the same DR3 positive haplotype was found in the CD and in the JDM patients. Interestingly in one family three different $C D$ patients have three different DR3 positive haplotypes and all have the same DR7 positive haplotype, while of the two JDM patients one is DR3 homozygous and the other is DR3/4 heterozygous.

From these data we conclude that the same DR3 haplotype can carry the susceptibility gene for CD and for JDM and that this susceptibility is very closely linked to/or identical with DR3.
SCREENING TEST FOR CHIIDHDOD COELIAC DISEASE: IgG or IgA ANTIBODY DETERMINATIONS ? A. Bürgin-Wolff, H. Gaze, M. Lentze, Depts. of Paediatrics, Universities of Basle and Berne, Switzerland

In an earlier study the diagnostic value of IgG-gliadin antibody determination for untreated coeliac disease in childhood showed $100 \%$ sensitivity and $84 \%$ specificity (fluorescent immunosorbent test, crude gliadin, J.Ped. 102, 655, 1983). We have tried to improve the specificity by testing not only the IgG but also IgA gliadin-ab.

\begin{tabular}{l|c|c} 
Results: & $\begin{array}{l}\text { disease controls } \\
\text { normal mucosa, } \mathrm{N}=31\end{array}$ & $\begin{array}{l}\text { untreated coeliac disease } \\
\text { flat mucosa, } \mathrm{N}=46\end{array}$ \\
\hline only IgA ab & 0 & 0 \\
only IgG ab & $5=16 \%$ & $\left.\begin{array}{r}6=13 \% \\
40=87 \%\end{array}\right\} 100 \%$ \\
IgG and IgA ab & 0 &
\end{tabular}

Conclusions: Determination of only IgG ab: $100 \%$ sensitivity, $84 \%$ specificity as in earlier study; determination of only IgA ab: only $87 \%$ sensitivity but $100 \%$ specificity; determination of IgG and IgA ab: All coeliac patients were ascertained. If IgG and IgA ab are present: coeliac disease is very probable. If only IgG ab: coeliac disease cannot be excluded. If neither IgG nor IgA ab: coeliac disease can be excluded. Biopsie results from various children's hospitals in Switzerland and FRG.SNF 3961-0.82 J.K. Visakorpi. Departments of Paediatrics and Micro-
biology, University Central Hospital, Tampere, Finland

A sensitive immunofluorescence test (FA) for IgA and IgG class serum reticulin antibodies (RA) was evaluated for the detection of coeliac disease (CD) in children. RA of any immunoglobulin class was found in 47 out of 1584 (3\%) children with miscellaneous disorders. Known $C D$ patients were excluded. Small bowel biopsy was performed on RA positive children (42) and on RA negative children (236) clinically suspected for having CD. The sensitivity for IgA-RA FA test to detect flat mucosa was $97 \%$, specificity $98 \%$ and positive predictive value $88 \%$. The corresponding figures for IgG-RA FA test were 59\%, $97 \%$ and $71 \%$, respectively. In children with flat mucosa the I IA-RA FA titres ranged from 1:50 to $1: 8000$ (GMT $1: 1288$ ). In the 4 "false positive" children the IgARA titre was $1: 100$. When children with flat mucosa were put on a gluten-free diet the IgA-RA rapidly decreased to undetectable levels.

It is concluded that IgA-RA FA test is a sensitive and specific indicator of active $C D$ in childhood. In screening for CD the probability of a false positive result is as low as $1.6 \%$; therefore the test can help to minimize unnecessary biopsies. 46 COELIAC DISEASE. M. Mäki, O. Hällström, T. Vesikari, 
IgA CLASS ENDOMYSIUM ANTIBODY/IgA-EMA/. AN IMMUNOLOGICAL MARKER OF COELIAC DISEASE AND School, Warsaw, Poland.

The authors describe a newly detected antibody of IgA class directed against endomysium of smooth muscle/IgA-EmA/ which appears to be specific for coeliac disease and dermatitis herpetiformis $(\mathrm{DH})$. A t the same time also anti gliadin antibodies (AGA) were determinated. Studies were performed on following cases: $28 \mathrm{CD}, 87 \mathrm{DH}$ and 188 controls healthy people 28 , colitis ulcerosa 15, other gut diseases 36 , bullous diseases 34 , scleroderma 34, SLE 7, other diseases 34/. The results were compared with jejunal biopsies. Both types of antibodies were studied by indirect immunofluorescence test using monovalent anti $\operatorname{IgA}$ and IgA conjugates and monkey esophagus as a substrate. The presence and titers of IgA-EmA strictly correlated with the clinical activity of the disease. In the florid CD, IgA-EmA were found in all cases. During the prolonged treatment with glutenfree diet the IgA-EmA fell to the undetectable levels and reappeared after gluten challenge. In patients who do not observe glutenfree diet strictly the titers did not drop significantly, contrary to those on the strict diet. In DH IgA-EmA were detected in ca $70 \%$ and in none of 188 controls. AGA did not show such evidenr correlation with a disease activity in CD. Detection of Importance besides its theoretical value may have a practical PROSTAGLANDINS IN SMALL INTESTINAL MUCOSA OF CHILDREN
WITH CELIAC DISEASE D. BransKi F. Karme $1 \mathrm{i}$. 48 WITH CELIAC DISEASE D. Branski, F. Karme $1 i^{x}$ E. Gross-Kieselstein, A. Abrahamov \& D. Rachmilewitz Dept. of Pediatrics, Bikur Cholim Hospital, \& Dept. of Gastroenterology, Hadassah University Hospital ${ }^{\times}$, Jerusalem, Israel.

Diarrhea is one of the main clinical symptoms in patients with celiac disease and it is attributed mainly to malabsorption. However, stimulation of intestinal electrolyte and fluid secretion, secondary to enhanced mucosal prostaglandin synthesis can also have a role in its pathogenesis. The aim of the study was to determine and compare prostanoid content in intestinal mucosa of 5 celiac patients and 6 control subjects. Prostaglandin $E_{2},\left(P_{G_{2}}\right), 6$ ketoprostaglandin $F_{1} \propto(6$ ketoPGF $\alpha)$ and Thromboxane $\mathrm{B}_{2}\left(\mathrm{TXB}_{2}\right)$ were determined by radioimmunoassay, and expressed as $\mathrm{pg} / \mathrm{mg}$ wet wt $+\mathrm{S} . \mathrm{E}$.

Results:

$\begin{array}{lccc}\text { Control } & 378 \pm 86 & \frac{\mathrm{PGE}_{2}}{124 \pm 53} & \frac{\mathrm{TXB}}{8 \pm 2} 2 \\ \text { Celiac } & 1581 \pm 161^{\times} & 908 \pm 437 & 118 \pm 40^{\times \times}\end{array}$

Thus, the increase in small intestinal $\mathrm{PGE}_{2}$ and $T \mathrm{XB}_{2}$ content in celiac patients may contribute to the diarrhea in active celiac disease.

Significantly different from control $\times p<0.001$ $x x p<0.025$

GASTRIC FUnCTION ABNORMALITIES IN COELIAC DISEASE.

49 G.Banchini, G.Gregori, G.L. de Angelis.

Department of Pediatrics, University of Parma, Ital

We studied gastric function in 6 children (mean age 8.8 yrs) affected by symptom less Coeliac Disease (CD) and in 6 children affected by functional recurrent abdo minal pain, matched by age and weight and chosen as controls. In all cases we evaluated fasting serum Pepsinogen I (PGI), fasting and after test meal serum Gastrin (GS) and basal and pentagastrin-stimulated gastric acid ouput. (6 $\mu \mathrm{g} / \mathrm{kg} \mathrm{s.c.).}$

Results

GS basal $\mathrm{pg} / \mathrm{ml}$

Coeliac Disease

Controls

GS peak $\mathrm{pg} / \mathrm{ml}$

$$
81.5+15.6
$$

n.s.

$64.2+9.2$

PG I $\mu g / m$ l

$320.5+113.5$

$p<0.02$

$125.8+25.5$

$B A O \quad m E q / \mathrm{kg} / \mathrm{h}$

$72.2+8.8$

$p<0.01$

$44.5+2.7$

$\mathrm{mEq} / \mathrm{kg} / \mathrm{h}$

$.273+0.040$

n.s.

$0.033+0.022$

mE q $/ \mathrm{kg} / \mathrm{h}$

$0.409+0.060$

$<0.05$

$0.202+0.020$

$0.272+0.030$

${ }^{*}$ )(basal acid output was absent in all cases of CD except one $(B A O=0.040)$ ).

In all patients with CD (diagnosed by ESPGAN criteria) GS and PG I levels returned into the normal range after 1 yr.of glutea free diet. Conclusions: Duodenal villous atrophy is an important in vivo model to study the physiopathology of the relationship between stomach and small gut. In untreated $C D$,gastric function seems to be different from controls. The return to normal levels of the gastric function with the regeneration of the small gut mucosa may depend from normalized activity of one or more factors, only partially known, as secretin or GIP, usually released by the same small gut mucosa.
PERIPHERAL BLOOD LYMPHOCYTE ACTIVATION BY PURIFIED GLIADIN FRACTIONS . EEFECT OF HIA DR 7 ANTIGEN ON THE

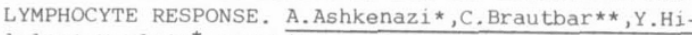
lel***,M.Klein*${ }^{\star}$ *Institute of Pediatric Research, the le1***,M.klein**Institute or Pediatric Research, the (roenterology and Nutrition, Kaplan Hospital Rehovot, **Dept of Immunology, Tissue typing unit Hebrew Universi ty and Hadassah Medical School, Jerusalem. $\star \star \star$ Dept of Genetics, Faculty of Agriculture, Hebrew University, Rehovot, Israel.

Peripheral blood mononuclear cells (PBMC) are stimulated by gliadine derived peptide fractions. This stimulation can be quantitated by $3 \mathrm{H}$ thymidine uptake. There are coeliac patients and normal controls whose PBMC respond to stimulation - responders and-non responders, the ones who does not have an increased $3 \mathrm{H}$ thymidine uptake often stimulation with gliadin peptides.

We tested the influence of the HLA make up on the ability to respond to stimulation by purified gliadin peptides in coeliac patients $(\mathrm{CD})$ and controls (NC), with known HLA make up.

We found the responders to fractions $B 3 G, B 314, B 3142$ and $B$ 3146 to be CD with HLA DR7 and the non responders DR-3. No effect was obtained with fractions 3141,3143 and 3145 . The normal cont rols response was absent or lower. The difference in response of the DR7 group of patients ( $\mathrm{n} 10)$ when compared to the DR-3 (N12) was very pronounced, $t=11.692$ for the pure peptide 3142 . We did not find any difference in the response of the DR7 and DR3 patients to the lectins PHA and Con A. This kind of approach, mainly using pure and defined antigens on definite CD patients with defined HLA make up will help in elucidating the pathogenesis of $C D$
51 SMALL BOWEL AND SERUM DIAMINE OXIDASE ACTIVITIES IN CHILDREN WITH CELIAC DISEASE. P. Forget $\%$, JL. Van Cutsem\%, C. Grandfils"\% and G. Dandrifosse $\%$ "Dept. Paediatrics, "Nopt. general and comparative Biochemistry, University of Liège, Liège, Belgium.

Diamine oxidase (DAO), an enzyme localized in mature enterocytes and whose activity can be measured either in small bowel biopsy tissue or in serum, is thought to be a marker of small gut functional integrity.

DAO activities were measured in small intestinal biopsies and in serum of control children and children with florid coeliac disease. The radiometric method was used (1).

Mucosal DAO activites were found to be significantly higher in control children than in children with coeliac disease (mean SEM : $486 \pm 39$ versus $171 \pm 30$ manomoles $\mathrm{h}^{-1} \mathrm{~g}^{-1}$ wet weight, $\mathrm{p}<0.001)$.

Similarly, serum DAO activities were significantly higher in control children than in children with coeliac disease (mean \pm SEM : $39 \pm 12$ versus $12 \pm 1.6$ picomoles $\mathrm{h}^{-1} \mathrm{ml}^{-1}$ serum,

$\mathrm{p}<0.002$ )

The lower serum activities associated with low mucosal values support the hypothesis that serum DAO is a marker of small intestinal functional integrity.

Our study shows that serum DAO can be a useful tool in the management of childhood coeliac disease.

(1) Okuyama T. et al. Arch. Biochem. Biophys. 95, 242, 1961
52

MITOGENIC ACTIVITY OF PURE PEPTIDES PREPARED FROM GLIADIN DERIVED FROM AN INBRED STRAIN OF WHEAT-KOLIBR I

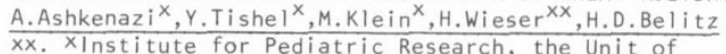
Pediatric-Gastroenterology and Nutrition, Kaplan Hospital, Rehovot. XXThe Institute for Food Chemistry The Technical University Munchen, West Germany.

The ability of pure peptides, derived from gliadin, to stimulate peripheral blood lymphocytes in vitro as measured by tritiated thymidine uptake was examined. Four groups of subjects were included in the study: 9 patients with coeliac disease (CD) consuming normal gluten containing diet (ND); CD-consuming gluten free diet (GFD): 15 normal controls (NC) and 7 gastrointestinal investigation (GII) patients consuming ND. In all groups examined the peptides caused an increase of the stimulation index (SI) 1.16 to 3.0 . The highest SI was obtained in the CD GFD group of patients and the most active fractions in this group were $3|4-5|$ $3.0+0.79$; $B 3 G-2.4+0.26$ and the pure peptide $3142-2 \cdot 14+0.3$. In the

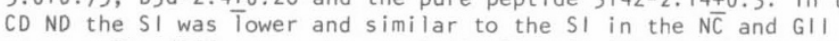
groups. The difference was statistically significantt $=2.2$ only between the CD GFD and NC groups stimulated by B3G. The mitogenic effect of peptide B3G and 314 was inhibited by mannan, the SI decreased from 1.94 (B3G) to 0.69 and from 2.01 (314) to 0.73 in the NC group and from 2.22 to 0.84 and 2.06 to 0.71 in the CD groups patients. The conclusion is that the gliadin derived peptides act as mitogens i.e. stimulate the thymidine uptake or peripheral blood lymphocytes of normal subjects and coeliac patients alike. 
MODULATORY EFFECT OF ADHERENT CELLS (AD) ON T-MEDIATED SUPPRESSION IN COELIAC DISEASE (CD).C.Pignata,R.Troncone,G.Monaco,S.Auricchio Dent. of Clinical Paediatrics, II Fac.of Medicine,University of Naples, Naples, Italy. $A D$ suppress many immune functions, including, in some experimental models, ConA-inducible T sunpressor cells (TS) by releasing soluble mediators, mainly prostaglandins (Pg)(Goodwin J.S., Cell. Immunol., 49:421,1980). We have found a failure of TS in some CD patien ts (Pignata C.et al.,Ped.Res.,17:426,1983). The aim of the present study was to investigate the role of $\mathrm{Pg}$-producing $\mathrm{AD}$ on the ConAactivation of TS in CD patients and in controls (CO), by both bloc king with $1 \mu \mathrm{g} / \mathrm{ml}$ indomethacin $\mathrm{Pg}$ production in 11 patients and adding activated $A D$ (cultured for 30 min or 5 days)(Veit B.C., Cell. Immunol., $72: 14,1982$ ) from 2 CD patients to control mononuclear cells (MNC)during ConA-induction of TS. Results showed that:1) MNC from 4 out of 5 patients with a failure of TS normalized when TS were induced in the presence of indomethacin. The percentage of ConA-induced suppression in the $11 \mathrm{CD}$ patients was enhanced by in domethacin (M \pm SD: $67 \pm 28 \%$ versus $41 \pm 35 \%$ wi thout indomethacin; $0.05>\mathrm{p}<0.1)$; enhancement was inconstant in $\mathrm{Cn} ; 2) 30$ min-precultured $A D$ from $C D$ patients inhibited the induction of TS in control MNC (100\% and $34 \%$ ), whereas control AD did not. An inaporonriate $A D$ activity may interfere with ConA-activation of TS in coeliac disease.

\section{CHILDREN WITH COELIAC DISEASE (CD). E.Ross ipal, H.Popper, H. Becker, Dept. Of Paed.}

The increase of intraepithelial lymphocytes and interstitial lymphocytic infiltration is a well known featur in activ CD. The aim of this study was to investigate the content of $T$ and $B$ cell subpopulations in the small bowel mucosa with respect to the amount of ingested gluten and time of withdrawel of gluten in the diet. The investigations were done in 7 infants and children with act ive $C D$, in 3 children in whom gluten had been withdrawn 2-4 weeks prior to biopsy and in 3 children who did not adhere strict to a gluten free diet. Six age matched children without $C D$ served as controls. Immunofluorescence studies were done using monoclonal antibodies OKT4, Leu 3a, OKT8, Leu 2a, OKT3, Leu 1 and Leu 7. B-lymphocytes were tested for HLA-DR and ATI reactivity and for their ability to produce IgG, IgM, IgA, IgE and IgD. Cells were. counted and expressed as cell/medium powerfield ratio (Magnif. x 250). We found no significant difference with respect to the absolute cell counts of the lymphocytic subpopulations in CD compared with the controls. Jet there showed to be a strong tendency in active $C D$ toward an increase of Tlymphocytes, helper and suppressor cells, natural killer cells and B-lymphocytes. The most obvious increase was that of the helper and suppressor cells. In our investigations most of the intraepithelial lymphocytes did not exhibit T-cell marker properties. 2-4 w. gluten free diet did not restore normal conditions.

DISTURBED IMMUNE REGULATION IN CELIAC DISEASE.(C.D.)

Y.Elitzur, O.Kuperman, S.Moses, S.Freier, S.Segal.
Department of Pediatrics \& Department of Immunology $\varepsilon$
Microbiology, Soroka Medical Center \& Ben-Gurion

University of the Negev, and Shaare Zedek Medical Center ${ }^{x}$,

Jerusalem.

The cause of C.D. is believed to be due to an aberration of the immune system, in particular cellular immunity. We studied lymphocyte responses to phytohemagglutinin (PHA) with and without $\alpha$ -gliadin in patients with celiac disease. Our patients were considered to have true C.D. if they had suspicious symptoms, abnormal biopsy, response to a gluten free and if the biopsy became abnormal again on gluten challenge after the age of 2 years. (Group A) Eleven patients with true C.D. were compared with 17 patients under 1 years old in whom an initial biopsy was abnormal (Group B). Retrospective analysis of our patients has shown that $50 \%$ of patients in this under 2 years old group are ultimately proven to have transient gluten allergy only. Control groups included patients with other intestinal diseases (Group C), and healthy adults (Group D). We found that our patients with true C.D. had a diminshed response to PHA when compared to groups $B, C$ and $D .(P<0.001)$. In the presence of $\alpha-g l i a d i n$ and PHA there was a rise of $40 \%$ in the response of lymphocytes from patients with true C.D. When compared with the other groups $(p<0.001)$. Our findings are compatible with the hypothesis that in C.D. the activity of suppressor cells in impaired in the presence of $\alpha-g l i a d i n$. J. Soares, P. Magalhães Ramalho. Department of Pediatrics. Hospital de Santa Maria. University of Lisbon. Portugal.

Intestinal biopsy is an essential procedure for the diagnosis of CMPSE. However, the number and timing of biopsies is still a controversial subject. Twenty infants clinically suspected of having CMP intolerance were put on a milk-free diet, during which they all improved. After this, they were submitted to a 1 st jejunal biopsy; a cow's milk challenge; and a 2 nd biopsy one to two days later. In 14 infants (group I) the period of milk withdrawall preceding the pre-challenge biopsy lasted 6 to 8 weeks; in 6 infants (group II) this period lasted $31 / 2$ to 4 months. All the infants reacted adversely to milk reintroduction. In group I no significative difference could be observed between preand post-challenge biopsies and this was due to the severity of mucosal damage still present in $1 \mathrm{st}$ biopsies. In group II pre-challenge biopsies still presented with mild or moderate villous atrophy, but a deterioration was evident in all after challenge. Intraepithelial lymphocite counts and mitotic index determinations before and after milk reintroduction were of no diagnostic help in either group. It is suggested that the diagnosis of CMPSE may rely on two biopsies, the 1 st after a period of milk free diet of not less than $31 / 2$ months and the 2 nd following milk challenge.

COW'S MILK PROTEIN INTOLERANCE (CMPI): DIFFERENTIATION R.Chianca, A.Guarino, A.Vegnete, A.Rubino. Inst.Ped. 2nd School Medicine University of Naples, Italy.

C.M.P.I. is responsible for a variety of G.I. signs and symptoms. However, it is unclear whether the type of reaction(upper or lo wer G.I.) is contant in the same patient on repeated challenges, and, if so, to what extent. We investigated 70 childrens ( 41 males, mean age $=6$ mos when first seen) with C.M.P.I. At oral challenge, 13 patient develped shock, 14 skin rashes and 43 diarrhea and/or vomiting. Of such 43 oatient, 23 showed signs of small intestinal involvement only ( $1 \mathrm{hr}$.blood $D$-Xylose test from $47.5 \pm 3.4 \mathrm{mg} / \mathrm{dl}$ before challenge to $20.4+2.0$ after it, reducing substances in the feces). The remaining 20 only showed large intestinal involvement (aspecific colitis at hystology, stool occult blood, fecal leukocytes-mainly eosinophils). Challenge was repeated (after a mean of 8 months) in 48 patients; of the 27 positive cases, $20(74 \%)$ again reacted in the same way. In 10 patients, CMPI did not subside by the age of 2 ; their age at onset $(2.3+0.2 \mathrm{mos})$ was younger $(P<0.05)$ that that $(5.5+0.7$ mos) of patients in which CMPI sudsided earlier. In conclusion: 1) G.I. Reactions to CMP challenge can be grouped in upper and lower intestinal; whether or not they reflect separate immunological mechanisms remains to be ascertained;2) such reactions, tend to be repetitive in the single patient; 3) late
onse.t CMPI runs a shorter course. 
A NEW BIOTIN-AVIDIN ENZYMEIMMUNOASSAY (ELISA) fo DETECTION OF COW'S MILK PROTEIN SPECIFIC I IE IN THE DIAGNOSIS OF COW'S MILK ALLERGY (CMA). M.S.Scotta, A.Plebani, C.De Giacomo, G.Maggiore, S. Guandalini A.M.Giunta, A.G. Ugazio. Dept. of Pediatrics University of Pavia, Napoli and Milano, Italy. High level of specific IgG can affect RAST results in the serologic evaluation of infants and children with CMA. Aim of this study is to compare with RAST a new ELISA method for cow's milk protein specific IgE which bypasses the interference by specific IgG. Patient specific IgE are first immunoadsorbed using microtiters plates coated with anti-human IgE then biothinylated cow's milk proteins are added, and if spesific $\mathrm{gE}$ binding occours the reaction is revealed colorimetrically by adding HRP-avidin conjugate. On 43 sera studied with RAST and ELISA, 12 were RAST positive and 15 ELISA positive. When only RAST results were considered positivity was present in $28 \%$ and when considering only ELISA positivity was presents in $35 \%$; when both RAST and ELISA were considered together percentage increased to $42 \%$. In the group of 17 patients with immediate symptoms results corrisponded in 12 and RAST was positive in 7, ELISA in 6 and when both RAST and ELISA were considered the percentage increased to $53 \%$. In patients with delayed symptoms results corresponded in 22 on 26 RAST was positive in 5, ELISA in 9 and the percentage remained 35 when considering RAST and ELISA together. Combined use of RAST and ELISA seems to offer the advantages of overcomming the limitations of each permitfing a realiable diagnosis of CMA in more
children that with elther laboratory test alone.

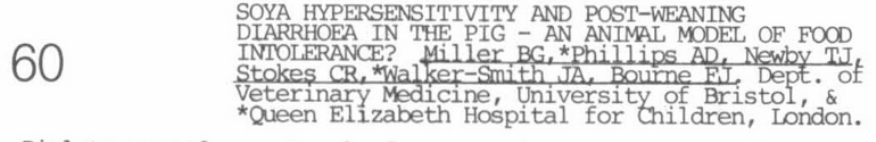

Piglets weaned prematurely for econamic reasons show an increased susceptibility to post-weaning diarrhoea. A transient immune hypersensitivity to dietary antigens is
postulated to underly the disease and experiments to evaluate
this were performed using soya protein.

Three groups of piglets were weaned aged 3 weeks onto a diet
with $22 \%$ soya as the sole source of protein. Group 1 with sacrificed at $0,1,2,5,7$ and 13 days post-weaning for
morphological studies. injections in the ear 24 hours prior to sacrifice. In Group 2 $(\mathrm{n}=8)$ xylose absorption was measured $0,2,5$ and 11 days post-weaning. Group $3(\mathrm{n}=6)$ were given soya as a supplement to sow s milk prior to weaning. Xylose
measured at 0 and 5 days post-weaning.

Soya feeding in groups 1 and 2 was associated with a period of welght loss, malabsorption, diarrhoea, villous atrophy, crypt hyperplasia and increased susceptibility to an E. colli diminished by day 13 In group 3 prior feeding with soya protein prevented malabsorption and diarrhoea. The results support the hypothesis of a transient immune hypersensitivity
and may represent an animal model of transient food intolerance
in children, albeit on a compressed time scale.

MILK FEEDING AND INTESTINAL PERMEABILITY CHANGES IN 61 INFANTS. L.T.Weaver, M.F.Laker, R.Nelson. Rov

Cow's milk formula (CMF) mav cause damage to the G-I mucosa in infants, and breast feeding is associated with enhanced macromolecular absorption in some species. Changes in permeation of the GIT to snall water-soluble molecules mav reflect these phenomena.

The non-metabolized markers lactulose and mannitol were used to study the changes in passive intestinal permeability of 26 infants during the first and at six weeks of age. 11 received breast milk, $7 \mathrm{CMF}$, and 8 soy formula. Intestinal permeability was measured from the urinary recovery of markers included in infant feeds and expressed as a lactulose: mannitol excretion ratio.

In common with preterm babies (WeaverL.T. Pediatr Res, 17: 420 (1983).), a dailv decline in mean excretion ratios occurred between davs 1 and 4 after starting oral feeds ( $\mathrm{p}=0.03$ ), and a further decline by 6 weeks ( $=0.003)$. Breast and sov-fed babies had lower mean ratios by dav 4 than CMF-fed babies ( $p \approx$ 0.05 ), but no significant difference between feeding groups was present at 6 weeks.

CMF feeding was not associated with a rising, nor breast feeding with a higher or more prolonged intestinal permeabilitv, to lactulose during the first week, or at 6 weeks of life. crypt cells were isolated from jejunal segments at intervals af ter birth up to adulthood. SC content was measured in each cell fraction by a sensitive immunoradiometric assay and compared to sucrase activity, an enzyme marker of the mature villus cell. Results: (1) adult rats showed a typical concentration gradient $f$ SC decreasing from the crypt base $(\bar{x}+\mathrm{SE}$ in crypt cells: $636 \pm$ $173 \mathrm{ng} . \mathrm{mg}$ prot. $\left.{ }^{-1}\right)$ to the villus tip $(\mathrm{x}+\mathrm{SE}$ in villus: $152+-$ $17 \mathrm{ng} . \mathrm{mg}$ prot. $\left.{ }^{-1}, \mathrm{p}<0.01\right)$ that was the reverse of the sucrase gradient; (2) in young pups (10 days), SC was virtually absent and rised markedly in villus and crypt cells of weanling rats (day 20), reaching adult levels by day 40; (3) the crypt to villus cell gradient of SC, absent up to day 20 , developed during the 4 th week; (4) treatment of 10-day-old rats with either corticosterone $\left(20 \mu \mathrm{g} / \mathrm{g} \mathrm{B} \mathrm{wt}^{-1}\right)$ or L-T4 $\left(2 \mu \mathrm{g} / \mathrm{g} \mathrm{B} \mathrm{wt}^{-1}\right)$ for 3 consecutive days induced sucrase activity but depressed SC content $(-64$ to $93 \%$ vs controls, $\mathrm{p}<0.01)$ in both villus and crypt cells. Conclusion: The crypt cell of the rat jejunum exhibits major changes in SC synthesis, beginning on day 20. The initiation of this ontogenic event is not under the control of the hormonal factors known to trigger the maturation of functions linked to the mature villus cell.

\section{3}

A LESION OF THE INTESTINAL BRUSHBORDER (BB) AS SEEN BY SCANNING ELECTRON MICROSCOPY (SEM) IN CHILDREN WITH ALLERGIC ENTEROPATHY (AE). J.R.Poley. Dept. Pediatr. Eastern VA. Medical School, Norfolk, VA.

To study events on the surface of the small bowel in $\mathrm{AE}$, biopsied mucosa was examined by SEM (JPGN $1: 63,1982)$ in 5 patients. Disaccharidase activities were measured, and villous height estimated by light microscopy. Sensitivity to offending food proteins

was determined by challenge and elimination experiments.
Patient Age Dietary SEM Findings

\begin{tabular}{lrr} 
mo. Protein & Activities \\
\hline 1. J.J. 4 Milk (cow) $\mathrm{SV}^{\star}$; damage $\mathrm{BB}$; loss of $\mathrm{GC}^{\star}$ & decreased
\end{tabular}

$\begin{array}{lllll}\text { 1. M.J. } & 9 & \text { Milk } & \text { SV; damage } \mathrm{BB} \text {; loss of } \mathrm{GC} & \text { decreased } \\ \text { 2. } & \text { decreased }\end{array}$

3. F.B. 14 Wheat Damage BB; loss of GC decreased

4. A.A. $18 \mathrm{Milk} / \mathrm{soy}$ Exc.mucus;damage BB;loss of GC normal

5. C.A. 30 Egg, beef Damage BB; loss of GC decreased
${ }^{\star}$ SV: shortening of villi; GC: glycocalyx

SV was moderate, and only seen in the two youngest children reacting to cows milk. The most impressive and constant finding in all mucosal specimens was that of damage to the BB, with loss of GC over wide areas. The BB lesion, appreciated by SEM, seems unique to $\mathrm{AE}$, as it has not been observed in children with chronic diarrhea of other cause. This lesion may make the mucosal surface more permeable to macromolecules and thus perpetuate (immunologic?, toxic?) injury. Furthermore, the disappearance of the GC seems responsible, in part, for the marked reduction of disaccharidase activities. The pathogenesis of the BB lesion remains obscure.

\section{STOOL PATHOGENS IN INFANTS, L.T. Weaver, P. Chapman C.R.Madeley, M.F.Laker, R. Nelson. Royal Victoria C.R.Madeley, M.F.Laker, R.Nelson. Ro.}

The relationship between diarrhoea and vomiting, excretion of stool pathogens, and intestinal permeability to passively absorbed markers was studied prospectively from birth to six months in 18 infants from a deprived area of Tyneside. Gastrointestinal symptoms were recorded daily, stool samples for microbiological analysis obtained weekly, and tests of intestinal permeability performed two monthly, or when possible pathogens were excreted. Intestinal permeability was measured from the urinary excretion of lactulose and mannitol included in infant feeds (Weaver L.T., Pediatr Res, 17: 420 (1983)). This is a sensitive method of detecting small intestinal damage in children.

468 stool samples were analysed and 74 permeability tests performed. Increased lactulose: mannitol excretion ratios were found on 13 occasions, in association with rotavirus excreation (3), adenovirus (4), echovirus (1), poliovirus (1), campylobacter (1), candida (2), no organism (1). In 5 cases diarrhoea and/or vomiting were also present. Raised permeability ratios returned to normal with termination of pathogen excretion. Virus excretion also occurred in the presence of normal permeability ratios, but only one baby (with diarrhoea and vomiting) exhibited an enhanced ratio in the absence of pathogen excretion.

An alteration in intestinal permeability may be an invication of mucosal damage by intestinal pathogens. 
We have shown that children with autoimmune $C A H$ have geneticallsuggested that this is a predisposing factor since similar findings are associated with autoimmune disorders in experimental animals. $C 4$ is coded for by two separate loci situated in the major histocompatibility region of chromosome $6, .12$ or more allotypes, including "null" variants have been described at each of these loci. To investigate whether $\mathrm{C} 4$ deficiency in CAH is associated with specific alleles, we have studied 20 such children and their parents. $C 4$ phenotype was determined by immunofixation of electrophoresed desialated samples, $C 4$ serum levels by nephelometry and $\mathrm{C} 4$ function by haemolytic assay. At least one null allotype was found in $18 \mathrm{CAH}$ patients whose genotype was deduced, 15 having low $\mathrm{C} 4$ concentration or function. The genotype was known in 24 parents; 20 had null variants, 10 of whom had low C4 levels or function. Null allotypes were present in 59 of 100 blood donors, significantly less frequently than in the patients $\left(x^{2} 6.9, p<0.01\right)$ or their parents $\left(x^{2} 5\right.$ $p<0.05)$. This study shows an association between deficient $\mathrm{C} 4$ and null variants of $\mathrm{C} 4$ in $\mathrm{CAH}$, but its pathogenic significance remains to be established.

Syndromic intrahepatic biliary hypoplasia remains clinically poorly defined and of uncertain prognosis. To determine the clinical course we have retrospectively analysed 20 cases with the following extrahepatic features: systolic murmur 95\%, empryotoxon $80 \%$, abnormal facies $75 \%$ and vertabral anomalies $33 \%$

15 presented with jaundice from birth, 2 with failure to thrive, 2 with bleeding, 1 with pruritus. Two died at 1 \& 4 yrs of cardiac lesions. The survivors range in age from $11 / 2$ to 15 yrs. 15 months (median 3 yrs. 7 months). All have persistent clinical or laboratory evidence of liver disease, al though jaundice has cleared in 7.9 have persistent splenomegaly and 7 cutaneous shunts. Pruritus developed in 17 at 4-24 months and persist in 15., Xanthalasma appeared at 14-74 months in 6 and remains in $4.77 \%$ have growth retardation, $72 \%$ developmental delay. 11 instances of symptomatic deficiency of Vitamin K, D or $E$ have been recorded.

Although liver biopsy at presentation showed normal architecture and no increase in hepatic fibrosis, the majority of children have a severe, chronic, handicapping illness with neurological, developmental or hepatic impairment.

ACTIVATED T LYMPHOCYTES IN CHILDREN WITH CHRONIC ACTIVE HEPATITIS (CAH). G Mieli-Vergani, A Yeo, L Alvigi, D Vergani, AP Mowat. Depts. Immunology \& Child Health King's College Hospital, London,

England.

Ia antigen is detected on T-lymphocytes when they are actively involved in immune-reactions, e.g. viral disease (mononucleosis) and immune-mediated disorders (rheumatoid arthritis, Grave's activation of $T$-lymphocytes plays a role in the immune -mechanisms leading to CAH we have determined numbers of la+ve T-cells in 11 samples from 9 children with $\mathrm{CAH}$. Controls were 15 agematched heal thy children and 14 children with other chronic liver diseases. T-lymphocytes were purified by $E$ rosetting and I+ve T-cells were detected by direct immunofluorescence with anti-la monoclonal antibody. Numbers of la+ve T cells were significantly higher in 5 patients with uncontrolled CAH (mean $8.2+$ SD 1.8) when compared to healthy controls $(2.8 \pm 1$ $\mathrm{p}<\overline{0} .01$, Rank test) and to other chronic liver diseases $(3.5+<0.01$, Rand test), but were normal in 6 treated patients with inactive disease $(2.9+1.3)$. Two patients with high numbers of la+ve T-cells at diagnosis showed normal values when retested during immunosuppressive treatment. Increased numbers of latve T-cells in CAH, but not in other chronic liver diseases, and their return to normal during effective treatment, suggest the participation of activated T-lymphocytes in the immunemechanisms leading to liver damage in $\mathrm{CAH}$.

ULTRASTRUCTURE OF THE LIVER IN LONG CHAIN ALIPHATIC ACID DISORDERS. J Scotto, O Dulac, P Aubourg,

67 F Porthault, D Alagille. INSERM U 56 \& Clinique de Pédiatrie, Hopital St-Vincent-de Paul, Paris, France.

In the liver of three young patients the ultrastructural finding of mesenchymal cells with spiked cytoplasmic inclusions containing trilaminar lamellar structures allowed us to individualize a clinical entity which was biochemically characterized by the presence of phytanic acid in the serum. The same inclusions with the same lamellar material have been described in other organs in cases of neonatal or fetal adrenoleucodystrophy (ALD). These forms of ALD are very different from the usual childhood form, specially in the genetic, but they have in common the presence of very long chain fatty acids in the serum. We report here identical ultrastructural observations in the liver of two children with Zellweger syndrome. The presence of very long chain fatty acids, which have been found in the serum of our children, has also been recently reported in some cases of Zellweger syndrome. Thus a biochemical relationship between neonatal ALD and cerebro-hepato-renal syndrome has been advanced.

The ultrastructural similarities reported here provide further evidence of a relationship between them and the infantile phytanic acid storage disease. An impaired oxidation of long chain aliphatic acid may be the common metabolic disturbance in these diseases.
A COMPARISON BETWEEN WILSON'S DISEASE(WD) AND INDIAN CHILDHOOD CIRRHOSIS(ICC), TWO COPPER STORAGE DISORDERS IN INDIAN CHILDREN MS Tanner, DG Sidhaye, SA Bhave, AN Pandit Dept Child Health,University of Leicester, UK, and Dept Pediatrics,KEM Hospital, Poona, India

Amongst 357 liver patients 7 ( 5 boys) with WD presented with hepatic disease (4), rickets (1), or a family history (2). They differed from 173 children with ICC (136 boys) in: age (WD $3-11$, mean 7.3 years; ICC $0.6-4.5$, mean 1.5 years), course, ceruloplasmin concentration, hepatic copper (WD range $311-1465$, mean 614 , ICC $n=108,1729 \pm 949 u g / g$ dry weight), and histology, 6 were cirrhotic, 3 with chronic aggressive hepatitis. Unlike ICC, orcein and rhodanine staining were scanty or absent. Electron probe analysis showed copper to be lysosomal in ICC, diffuse in early WD. Neurological abnormalities occurred in 2 cases of WD (age 9 and 11 years) with KF rings and in 2 siblings (age 9 and 14 years) No familial association of ICC and WD occurred.

Delayed referral, variable symptomatology, and negative copper staining contributed to late diagnosis and a poor prognosis in 6 out of 7 cases of WD.

$70 \quad \frac{\text { CHOLEDOCHAL CYST AND PANCREATITIS }}{\text { Y. Yamashiro, T.Miyano, K. Suruga, H. Shimomura, }}$
$\frac{\text { K.Suda, M.Matsumoro and H.Nittono. Dept. of }}{\text { Pediatrics, Pediatric Surgery and Pathology, }}$
Juntendo University School of Medicine, Tokyo, Japan.

Choledocho-pancreatic end to side ducta. anastomosis was performed in 40 puppies as an experimental model of abnormal choledocho-pancreatico ductal junction ( $A C$ PDJ). As a result, various degrees of common bile duct dilatation developed in all puppies. Histological change in the pancreatic duct was less prominent than that in the common bile duct but histologically proved choronic pancreatitis was found in 3 out of 23 sacrificed dogs. Reflux of pancreatic juice into the common bile duct readily and continously occurred and pancretic enzymes in bile aspirated from the dilated choledochus were activated. Total bile acids level and composition ratio of taurodeoxycholic acid to total bile acids were increased within a few months after the anstomosis. These findings suggest that ACPDJ, which is often found in the patients with choledochal cyst, is an important oetiologic factor not only for choledochal cyst but also for pancreatitis, and bile acids play an important role in the mechanism of pancreatic enzyme activation under the condition of ACPDJ. 
"SCLEROSING CHOLANGITIS" IN CHILDREN WITH IMMUNODEFICIENCY SYNDROME (IDS). B. Descos, F. Brunelle, A. Fischer, M. Hadchoue 1, 0. Bernard, C, Griscelli, D. 4 children (age 18 mos, 10 yrs) presented with bile duct (BD) abnormalities and IDS, consisting of common variable hypogammaglobulinemia ( 1 case), combined IDS with defective HLA antigens expression (2) and cellular IDS with cartilage hair hypoplasia syndrome (1). 3 had severe serum and secretory IgA deficiency. All had had chronic diarrhea and one bacterial cholangitis. On admission all had firm hepatomegaly without jaundice, raised transaminases and alkaline phosphatases. Ultrasonography showed dilatation of the extrahepatic BD in all, gallbladder sludge in 3 and portal hypertension in 2. Percutaneous transhepatic cholangiography disclosed dilated extra- and intrahepatic BD with luminal irregularity and segmental narrowing. Filling defects were present in 2 children with a progressive narrowing of the distal common BD. In the others there was an abrupt stricture of the distal common $\mathrm{BD}$. However passage of contrast medium into the duodenum was always observed. Liver histology was normal in 2 and showed portal fibrosis with ductular proliferation in the others, After a follow-up of 1 to 3 years, the clinical, biological and/or ultrasonography condition appeared stable, but prognosis is uncertain. These results indicate that children with IDS and hepatomegaly should be investigated for $B D$ abnormalities, and suggest various mechanisms for the lesions : infections or intrinsic abnormalities of bile, inflammation of the papilla and/or inflammatory disease of the BD similar to sclerosing cholangitis.

BILIARY IMMUNOGLOBULINS AND SECRETORY COMPONENT (SC) 72 IN CHILDREN. F. Rachman, S. Iscaki, F. Gauthier, O. Bernard, D. Alagille. INSERM, U 56, Bicêtre Inst. Fasteur, Paris, France.

In adults, the liver provides some secretory IgA (sIgA) to the gut fluid via the bile ducts. IgA binds to bile duct membranelinked SC and is transfered into the duct lumen as sIgA. In children, however, developmental physiology of immunoglobulin and $\mathrm{SC}$ secretion into bile is not known. Biliary SC (radial immunodiffusion), IgA, IgG and IgM (immunonephelemetry) were measured in 7 children with normal bile ducts (age : 12 hrs - 6 yrs) and in 4 children after surgery for biliary lithiasis (age : 2 mos 11 yrs). SC was detected from birth, its concentration raising with the age of the child. IgG, also detected from birth, remained below $100 \mu \mathrm{g} / \mathrm{ml}$. Only trace-amounts of IgA were observed until 3 months of age, the concentration then increasing from 16 to $310 \mu \mathrm{g} / \mathrm{ml}$. IgM levels were high in children over 2 years (392 to $770 \mu \mathrm{g} / \mathrm{ml})$. SC was also detected in gallblader fluid of 7 children with biliary atresia restricted to the hepatic ducts, at a level similar to that of normal children of the same age. Immunoperoxidase studies showed the presence of SC in the gallblader epithelium of 4 children with the same disease. These results (1) indicate that synthesis of $\mathrm{SC}$ by the biliary epithelium occurs from birth; this may explain the high levels of sIgA in sera from cholestatic infants, (2) show that secretion of IgA in bile is low during the neonatal period ; this may explain the high rate of cholangitis in infants after surgery

\section{3}

INCREASED SERUM SECRETORY IgA (sIgA) IN CHILDREN : A PROBABLE INDEX FOR BILIARY DUCT LESIONS. F. Rachman, S. Iscaki, 0. Bernard, D. Alagille. INSERM, U 56, Bicêtre; Inst. Pasteur, Paris, France.

The liver is involved in IgA homeostasis and, in humans, provides some IgA to the gut fluid via the bile ducts. Only trace-amounts of sIgA are detected in normal sera while elevated levels are described in liver diseases. To assess if serum sIgA levels can be considered as an index of biliary tree lesions, we quantified serum sIgA in 178 children (11 ds-14 yrs) with extra and intrahepatic biliary atresia, nonstructural cholestasis, $\alpha 1$ antitrypsin deficiency and chronic hepatitis B. Sera from 23 normal children were taken as controls. Means for cholestatic diseases $(146 \mu \mathrm{g} / \mathrm{ml})$ were significantly higher than for chronic hepatitis B $(79 \mu \mathrm{g} / \mathrm{ml})$, $\mathrm{p}<0.001), \alpha 1$ antitrypsin deficiency with cirrhosis $(95 \mu \mathrm{g} / \mathrm{ml}$, $\mathrm{p}<0.02)$ or without cirrhosis $(20 \mu \mathrm{g} / \mathrm{ml}, \mathrm{p}<0.0001)$ and controls $(19 \mu \mathrm{g} / \mathrm{ml}, \mathrm{p}<0.0001)$. sIgA was significantly higher in patients with bile duct diseases $(208 \mu \mathrm{g} / \mathrm{ml}$ in intrahepatic and $136 \mu \mathrm{g} / \mathrm{ml}$ in extrahepatic biliary atresia) than in nonstructural cholestasis $(112 \mu \mathrm{g} / \mathrm{ml}, \mathrm{p}<0.001$ and $\mathrm{p}<0.05)$. However, the large range of sIgA levels, possibly due to the variable severity of bile duct injuries in each patient, prevents its use for distinction between intra and extrahepatic disorders. Nevertheless, in $\alpha 1$ antitrypsin deficiency, the level of sIgA in serum may be useful as an index of cirrhosis since $15 / 17$ children with confirmed cirrhosis showed an elevation while 8 children with no cirrhosis had levels similar to the controls.
Bile acid secretion and exocrine pancreas function were determined quantitatively after iv stimulation with pancreozymin secretin using the method of perfusion of the small intestine. We examined patients with extrahepatic biliary atresia (group I, age: 1 $4 \mathrm{~m}$ ), with intrahepatic cholestasis (group 11 , age: 3 - $32 \mathrm{~m})$, and with normally functioning pancreas and liver (group III, age: $5-42 \mathrm{~m}$ ).

Results: The table shows the mean values per kgBW/ 50 min. In patients with cholestasis the secretion of bile acids and the pancreas function is decreased, particularly in cases of extrahepatic atresia.

\begin{tabular}{lrrrr} 
group & I $(n)$ & \multicolumn{1}{c}{$11(n)$} & \multicolumn{1}{c}{$111(n)$} & \\
\hline bile ac: & $1,3(6)$ & $4,7(7)$ & $40,6(9)$ & umol \\
trypsin: & $51,5(3)$ & $231,0(7)$ & $851,8(24)$ & units \\
1ipase : & $21,1(5)$ & $31,6(7)$ & $92,9(24)$ & units \\
water : & $1,0(6)$ & $3,8(7)$ & $5,7(23)$ & ml
\end{tabular}

Conclusion: Cholestasis leads to exocrine pancreas insufficiency (pseudo-pancreas insufficiency (1)). so that substitution with pancreas enzymes becomes necessary

1. NIESSEN, K. Mschr.Kinderheilkd. 128:301 (1980)

BUDD-CHIARI SYNDROME (BCS) IN CHILDREN: ETIOLOGY AND OUTCOME IN 20 CASES. O.Bernard, S.Gentil, F.Brunelle, M. Hadchouel and D. ATagiTTe. INSERM U 56 \& Dept de pédiatrie, Hốpital de Bicêtre, 94270 Bicêtre, France. We studied retrospectively 20 children in whom angiography or autopsy had shown obstruction of one or several major hepatic veins. Initial symptoms occurred at age 12 mos to 11 yrs (mean 4 yrs 10 mos) and consisted of refractory ascites (4 cases), abdominal pain (3) general fatigue (3) or fortuituous discovery of hepatomegaly (10). Needle biopsy of the liver showed signs of outflow block in 13 of 14 children studied. Ul trasonography showed abnormal hepatic veins in 16 of 17 children studied. Percutaneous hepatic venography demonstrated hepatic vein obstruction in all 15 children studied. Children could be divided in 3 etiological groups: secondary (amoebic abscess, liver tumor) in 2; due to venous malformation (stenos is of the inferior vena cava -IVC- and/or hepatic veins) in 4; or "idiopathic" in 14. Surgical recanalization of the atretic IVC was performed in 2. Portal-systemic shunts (PSS) were performed in 12. Three children who presented with refractory ascites died postoperatively. In the 9 others, clinical and biological conditions of the liver remained stable or improved. (Follow-up: 6 mos $-31 / 2$ yrs). Surgical liver biopsy carried out in 2 children 1 and 2 yrs respectively after PSS showed a striking improvement in liver histology. These results (1) indicate that in children BCS may remain clinically well tolerated, (2) show that a combination of liver needle biopsy, ultrasound and transhepatic venography allows proper diagnosis in most instances and (3) suggest that early PSS may prevent further deterioration of liver condition.

THE ABSORPTIVE FUNCTION OF COLONIC AGANGLIONIC INTESTINE: IS THE MARTIN PROCEDURE RATIONAL? A Heath, 76 L Spitz, P J Milla. Depts of Child Health and Paediatric Surgery, Institute of Child Health, London The Martin procedure has been proposed as a useful operation in long segment Hirschsprung's disease but considerable use is made of aganglionic gut. Whether the aganglionic segment contributes to fluid and electrolyte reabsorption in the refashioned rectum is not known. We have modified the technique of non-equilibrium dialysis of the rectum to simultaneously measure electrolyte transport and transmural potential difference (PD) in age-matched control children $(C)(n=6)$ and those with Hirschsprung's disease (HD) $(n=6)$ prior to operation. In $\mathrm{C} \mathrm{Na}^{+}$was absorbed electrogenically $\left(158 \pm 16 \mathrm{SEM} \mathrm{nmol} / \mathrm{min} / \mathrm{cm}^{2}\right)$ and was greater than $\mathrm{Cl}^{-}(127 \pm 13)$. K $\mathrm{K}^{+}$secretion was passive and greater than $\mathrm{HCO}_{3}^{-}$ secretion. In HD both $\mathrm{Na}^{+}$absorption $(170 \pm 10)$ and

$\mathrm{Cl}^{-}(187 \pm 10 \mathrm{p}<0.01)$ were greater than in $\mathrm{C}$ with $\mathrm{Cl}^{-}$absorption exceeding $\mathrm{Na}^{+}$. PD was higher $(30 \pm 5$ vs $40 \pm 1 \mathrm{mV} \mathrm{p}<0.02)$ with an associated increase in $\mathrm{K}^{+}$secretion. $\mathrm{HCO}_{3}^{-}$secretion accounted for the difference between $\mathrm{Na}^{+}$and $\mathrm{Cl}^{-}$absorption.

These data clearly show that aganglionic colon transports electrolytes and in the Martin procedure the refashioned colorectum contributes to overall colonic salvage of electrolytes. Furthermore it suggests that the Martin type operation may have a role in those with total colonic aganglionosis in whom excessive electrolyte loss remains a problem. 
ISOLATION AND CHARACTERIZATION OF TWO PARTICLE BOUND MECONIAL DIPEPTIDYL-AMINOPEPTIDASES IV (DIP)s WHICH ARE DIFFERENT FROM THE ADULT HUMAN ENZYME. C.Caporale, la,M.F.Molinaro,F.Santamaria,S.Auricchio.Dept.of CliniA.Fontanella,M.F.Molinaro,F.Santamaria, S.Auricchio.Dept.of CliniItaly.

Studies of crude fetal and meconial enzymes (Auricchio S. et al. J.of Ped.Gastroent.Nutr., $\underline{3}: 28,1984)$ and of purified meconial $01 \underline{i}$ goaminopeptidases (Auricchio S. et al. Ped.Res.,17: 422, 1983) have demonstrated the presence, in fetal brush border and in meco nial particles, of sucrase and peptidases different from the corresponding adult enzymes. After triton solubilization of meconium particles of at term newborns, two DIPs were separated by ion exchange chromatography. The quantitatively major form (DIP II) was purified to homogeneity. When compared to the adult enzyme, both meconial DIPs have the same molecular weight $(265,000)$, bu't a dif ferent affinity to Helix-pomatia- and lentyl-lectin. DIP II which is formed by two identical subunits of MW 130,000 , also has a low er isoelectric point and a higher electrophoretic mobility than the adult enzyme; the electrophoretic mobility of DIP II is not decreased by neuraminidase digestion. These results suggest that meconial and adult DIPs are glycoproteins with a different carbohydrate structure.

\section{8}

INTESTINAL LACTASE KINETIC STUDY AND DIET EFFECT IN RATS. I.C.M. Terra; R.C. de Angelis; J.v. Martins cal Sc. Inst./São Paulo University/Brazil.

Dams (rats) were fed with different diets during gestation and lactation: a - rice and beans, $12 \%$ of protein (RB, 12); b casein, 12\% (Cas, 12); c - casein, 20\% (Cas, 20). In the offsprings it was investigated the intestinal lactase affinity (L-A) for lactose substract (Lo-S) at weaning and after 30 days of: a - the same diet of the correspondent Dam; b - as in -abut the diets were added with $10 \%$ of lactose. The small intestine of the offsprings were ressected in part of the animals at weaning or after the 30 days of diet, and (L-A) determined by kinetic study of $\mathrm{Km}$. (L-A) was higher as: Cas, $20>$ Cas, 12> RB12, and all these values were enhanced by lactose in the diet; the $\mathrm{Km}$ increased with age. The results suggest that both "quantity" and "quality" of the diet's protein, as well as age, play an important role in the affinity of the enzyme therefore kinetic studies are recommended in order to understand better the (L-A) $x$ (Lo-S) reaction in different nutritional status.

STIMULATION OF INTESTINAL BRUSH-BORDER ENZYMES (BBE) IN SUCKLING RATS BY A SINGLE DOSE OF 16,16-DIMETHYL 79 PROSTAGLANDIN E 2 (PGE). M.J. Lentze, H.R. Koelz, Unit, Inselspital, University of Berne, Switzerland.

Previous studies (GE 84:1210,1983) have shown that repeated treatment of suckling rats with PGE activates BBE. In the present study we tested whether a single dose od PGE also stimulates intestinal BBE. Methods: Late on the 5 th and 11 th day 2 groups of 8 rats were treated once with $100 \mu \mathrm{g} / \mathrm{kg}$ PGE or an identical volume of $\mathrm{NaCl}$ by intragastric instillation. Rats were killed $16 \mathrm{~h}$ after treatment. Intestines were examined blindly by light microscopy and BBE measured in proximal small bowel. Results: PGE significantly increased trehalase, maltase and villus length on the 6th and all enzymes on the 12 th day (table).

\begin{tabular}{|c|c|c|c|c|}
\hline & \multicolumn{2}{|c|}{6 th day } & \multicolumn{2}{|c|}{12 th day } \\
\hline & Control & PGE & Control & PGE \\
\hline Villus length & $444 \pm 9$ & $560 \pm 22 * *$ & $576 \pm 19$ & $610 \pm 16$ \\
\hline Crypt depth" & $90 \pm 7$ & $111 \pm 8$ & $108 \pm 3$ & $98 \pm 12$ \\
\hline Sucrase" & $0.28 \pm 0.02$ & $0.32 \pm 0.03$ & $0.75 \pm 0.03$ & $1.01 \pm 0.06 * *$ \\
\hline Trehalase" & $0.54 \pm 0.01$ & $1.54 \pm 0.11 * *$ & $1.21 \pm 0.09$ & $3.18 \pm 0.27 * *$ \\
\hline Maltase" & $39.4 \pm 1.9$ & $49.4 \pm 1.8^{* *}$ & $41.5 \pm 2.5$ & $62.5 \pm 3.5^{* *}$ \\
\hline Lactase ${ }^{\circ}$ & $27.4 \pm 3.8$ & $33.2 \pm 0.8$ & $34.7 \pm 2.5$ & $44.1 \pm 2.0 *$ \\
\hline
\end{tabular}

Conclusion: In suckling rats a single dose of $\mathrm{PGE}$ stimulates the function of small intestinal mucosa on the $12 \mathrm{th}$ and in addition the structure on the 6th day suggesting accelerated development. (Supported by SNF 3.846.81)
Enterokinase determination, using trypsinogen as substrate is hampered by the activation process of trypsin (Tijdschr Gastroenterol $19: 231,1976)$. The proposed method is based on the determination of trypsinogen in the presence of soybean trypsin inhibitor. The reaction mixture consists of $50 \mu l$ of $0.25 \mathrm{M}$ cacodylate buffer $\mathrm{pH} 6.0,50 \mathrm{ul}$ of trypsinogen solution $10 \mathrm{mg} / \mathrm{ml}$ of $1 \mathrm{mM} \mathrm{Hcl}, 50 \mu \mathrm{l}$ of trypsin inhibitor solution $10 \mathrm{mg} / \mathrm{ml}$ of water, 50 Hl of $5 \mathrm{mM} \mathrm{crea-}$ tinine as internal standard, water and enzyme solution up to 250 4l. At regular time intervals, $10 \mu l$ of the incubation mixture is analysed isotachophoretically (Electrophoresis $\underline{3}: 262,1982$ ).

Conclusions : (1) Since high amounts of added trypsin or chymotrypsin are ineffective, the hydrolysis of trypsinogen seems to be affected by enterokinase only. (2) Under the conditions of assay, enterokinase activity can be determined in undiluted duodenal juice, even in the presence of pancreatic proteases, and in small intestinal mucosal homogenates. (Grant 3.0026.75, F.G.W.0.)

THREE-DIMENSIONAL DISPLAY OF ANAL CANAL MOVEMENT: A DYNAMIC PRESSURE PROFILE IMAGING TECHNIQUE. M.Sakaniwa Dept. Paediatric Surgery, University of Tsukuba, Japan An image processing system has been devised that allows anorectal movements to be visualized and displayed threedimensionally by analysis of pressure data obtained by anorectal manometry. Four polyethylene tubes (ID $1 \mathrm{~mm}$ ), with respective side holes, were glued together so that simultaneous recordings of pressures at $0.5,1.0,1.5$ and $2.0 \mathrm{~cm}$ from the anal margin were possible. Pressure values were fed into a microcomputer via an A/D converter every second for 20 minutes, obtaining the real-time pressure profiles of the anal canal. After the examination, the pressure profiles were arranged on the time axis and displayed three-dimensionally. The examination was performed on 7 normal children, 24 cases of chronic constipation, 11 cases of Hirschsprung's disease and 6 cases of anorectal malformations. Analysis of normal recto-anal inhibitory reflex (RAI) showed that the pressure decrease started initially in the proximal part of the anal canal. No rebound contractions were observed in the proximal nor in the distal part of the anal canal. In cases of chronic constipation the RAI revealed poor relaxation of the anal canal, especially in the proximal portion. In Hirschsprung's disease, movements of the anal canal were not at all influenced by rectal stimulation.

This technique can give new insights into disordered anorectal function.
FASTING SMALL INTESTINAL MOTOR ACTIVITY IN CHRONIC IDIOPATHIC INTESTINAL PSEUDOOBSTRUCTION (CIIP).

\section{E R Wozniak, T R Fenton, P J Milla. Hospital for Sick} Children \& Institute of child Health, London

CIIP usually presents in childhood and may be due to disease of smooth muscle, enteric nerves or alterations of their neuroendocrine environment. We have studied the functional effects of these disease processes using constantly perfused naso-jejunal catheters and simultaneously recording motility and myoelectric activity in 9 children. In 4 neonates with a myopathy, migrating motor complex (MMC) like activity was present but both pressure $(27.5 \pm 8.5 \mathrm{~cm} \mathrm{H} O$ controls $63 \pm 19.2 \mathrm{p}<0.02$ mean \pm ISD) and electrical activity was of low amplitude (3.8 $\pm 0.8 \mathrm{mV}$ controls $9.65 \pm 1.5$ $\mathrm{p}<0.001)$ and not propagated. Three children $(7-14 \mathrm{yrs})$ had a peripheral and autonomic neuropathy. Amplitude of both pressure $(63 \pm 19.2 \mathrm{~cm} \mathrm{H} O)$ and electrical activity $(9.65 \pm 1.5 \mathrm{mV})$ was normal but abnormalities of propagation with broad ill-formed complexes occurred. In one neonate both a neuropathy and myopathy was present. MMC like activity was propagated abnormally and was of low amplitude. In one further child normal cyclical fasting activity was present but the electrical slow wave was of increased frequency ( $13.5 \mathrm{cpm}$ controls $11.5 \pm 0.8)$. High BP and absent colonic activity suggested increased adrenergic activity which responded well to pharmacological blockade. These studies show that distinct disease processes causing CIIP can be distinguished using manometric and myoelectric recording techniques. 
AGE DEPENDENT VARTATIONS OF THE HUMAN MIGRATING MOTOR COMPLEX (MMC). T R Fenton, P J Milla.

Using constantly perfused triple lumen catheters we have studied upper small intestinal fasting motility and myoelectric activity in children undergoing intestinal intubation during investigation for suspected GI disease. Three groups were studied (no GI disease 8; irritable bowel syndrome 26 and organic GI disease 27). No significant differences were present in the parameters of the phase 3 of the MMC in the three groups. However a marked increase in phase 2 activity was seen in $13 / 27$ patients with organic GI disease compared with only $1 / 8$ with no GI disease and $3 / 23$ with IBS. With increasing age there was a marked increase in the propagation velocity (PV) and decrease in the duration (DUR) of the MMC. The Basic Electrical Rhythm (BER) also increased slightly:

$\begin{array}{llllll}\text { Age } & \mathrm{n} & \text { PV } & \text { DUR } & \text { BER } & \\ 0-4 & 24 & 7.8 \pm 7.1 & 9.3 \pm 4.8 & 11.5 \pm .8 & \text { (ISD) } \\ 8-14 & 17 & 18.4 \pm 10.7^{*} & 5.5 \pm 1.4^{*} & 12.0 \pm .4 * & { }^{*} \mathrm{p}<0.001\end{array}$

The increase in PV of the MMC would account for the constant cycle length seen in children despite the increasing length of the intestine with age. These age dependent variations must be considered when abnormalities in disease states in childhood are sought. Phase 2 activity is difficult to quantify but the increases seen in our patients might contribute to the pathogenesis of their symptoms.

THE DOUBLE-SAMPLING METHOD FOR GASTRIC EMPTYING (GE) REASSESSED. PT Jackson, JFT Glasgow, AA Greenfield,

\section{IJ Carré, Dept. Child Health, The Queen's University \\ 84 IJ Carré, Dept. Child Health, The Queen's University}

GE may be abnormal in certain disorders of the oesophagus and stomach, but has seldom been studied in childhood. As a prelude to in vivo studies of GE profiles in 'sick' infants, our aim was first to validate in vitro a reliable method (with its mathematical formula) for measurement of gastric volume(GV). This was measured in a 'glass stomach' using 130-160 ml of phosphate buffer as 'feed' with phenol red as marker. The double sampling George Method ${ }^{1}$ was compared 8 times with 2 modifications 2 , 1 devised by AAT, theoretically likely to improve accuracy of measured GV. To simulate GE and secretion, an aliquot was withdrawn from the flask and a very small volume of acid injected, each on 5-6 occasions. After each pair of manipulations, the difference between the known and measured GV was calculated. The mean difference, using the George Method was $21 \pm 2.2 \%(M \pm S E M)$ compared to $5.1 \pm 0.7 \%$ for the other two $(p<0.001)$, which individually gave similar results. Respective maximum differences which usually occurred after the third maniputation, were $63 \%$ compared to $17 \%$.

Conclusion: Accuracy of GE measurements is significantly improved by the suggested modifications although sizeable errors in GV may still occasionally be found.

${ }^{1}$ George JD. Gut, 1968, 9, 237.

${ }^{2}$ Hurwitz A. Gut, 1981, $22,85-93$.

\section{5}

GASTRIC EMPTYING(GE) IN PARTIAL THORACIC STOMACH(PTS) (HIATAL HERNIA) AND IN NON-SPECIFIC VOMITING IN

INFANCY. P. Jackson, J.F.T. Glasgow, I.J. Carre, Dept.

Child Hea ith, The Queen's University of Belfast.

Prolonged GE is a feature of hiatal hernia in adults and might be the cause of large projectile vomits common in infants with this abnormality. For these reasons GE was measured in 16 babies with $x$-ray evidence of PTS (7 mean age $0.4 y r ; 9-1.4 y r$ ) and 11 'controls with non-specific vomiting $(0.6 \mathrm{yr})$ in whom barium fluoroscopy was norma ${ }^{1}$. For 2 hours after the normal amount of a standard milk feed containing polyethylene glycol, gastric volume was measured using a previously validated, double-dye dilution technique modified by Hurwitz ${ }^{2}$. The volume of gastric secretion was allowed for in calculating the gastric emptying. Using Student's t test, no significant differences were found in gastric volume, $\frac{1}{2}$ emptying times, emptying rates or in \% feed emptied by $30,60,90$ or 120 minutes. Further, the paired t test failed to reveal any change in GE in 7 younger PTS patients following 13 weeks of postural therapy, nor in Belsey procedure.

Conclusions: These findings do not support those of Hillemeier et $\mathrm{I}^{3}$. They do not suggest a strong patho-genetic link between projectile vomiting in PTS and delayed GE, nor the mechanism by which postural therapy alleviates symptoms.

${ }^{1}$ Carré IJ(1979). In Report of the 76th Ross Conference on Gastroesophageal Refiux.

${ }^{2}$ Hurwitz $A(1981)$. Gut 22, 85-93.

${ }^{3}$ Hillemeier $A C$ et al. (1981). J.Pediat. 98, 190-193.
CLINICAL ASSUCIATIONS OF NUR:ALK AGUNT

Small round structured viruses with morphological features of Norwalk agent were detected by electron microscopy in 42 stouls from 25 children out of a total of 1360 stools examined from Narch 1982-jept. 1983. 16 children developed hospital acquired acute diarrhoea.7 of these had other stool viruses at the same time. 9 children were admitted direct to the gastroenteritis unit but in 5 there were other clinical problems.All children had diarrhoea but vomiting was not a feature of all children. The illness was mild. None required intravenous fluids. None developed sugar intolerance. 3 children who had rota and astrovirus infection as well had delayed recovery, one developing cow's milk protein intolerance. There was a clear seasonal pattern for diagnosis namely spring(April). In this study ivorwalk agent was not associated with winter vomiting disease.

\section{7} ENTEROTOXIGENIC ESCHERICHIA COLI. S. Knutton, P. Ristaino, D.R. Lloyd, M.M. Levine. Institute of Child Health, University of Birmingham, UK. \& Center for Vaccine Development, University of Maryland, USA Three different surface antigens designated coli surface-associated antigens CS1, CS2 and CS3 have been identified in enterotoxigenic Escherichia coli (ETEC) bearing colonization factor antigen II (CFA/II). CSI and CS2 have been shown to be fimbrial in nature but the morphology of CS3 has not been described. Since most CFA/II-positive ETEC possess CS3 (in addition to CS1 or CS2) we undertook studies to identify this antigen and document its morphology. Visualisation of bacterial cells of ETEC strains M424C1 (CS1, CS3) and 344 (CS2, CS3) by negative staining revealed two morphological distinct surface appendages: prominant $\sim 6-n m$ long rigid fimbriae and very fine $\sim 2-n m$ wiry, fibrillar fimbriae. Examination of strain E9034A (CS3) revealed only the fine, wiry fimbriae. That these structures represent CS 3 was confirmed by immune electron microscopy using monospecific antiCS1, anti-CS2 and anti-CS3 and a gold immunolabelling technique. Anti-CS1 and anti-CS2 coated the $\sim 6-n m$ rigid fimbriae on strains M424Cl and 344 respectively but did not coat the $\sim 2-n m$ fibrillar organelles. In contrast, anti-CS3 coated the fine, wiry, fibrillar structures on strains $\mathrm{M424 \textrm {Cl }}, 344$ and E9034A confirming them as CS3. No labelling occured with bacteria grown at $18^{\circ} \mathrm{C}$, conditions known to supress expression of CFA/II fimbriae. In purified form CS3 appeared structurally identical as when on the surface of
bacteria.

EFFICACY OF CHOLESTYRAMINE AT AN EARLY STAGE OF ACUTE DIARRHOEA IN INFANTS. M.Mäki, E.ISOlauri, T.Vesikari. Dept. Paediatrics, Tampere University Central Hospital, Tampere, Finland

Cholestyramine is effective in shortening acute infantile diarrhoea of several days' duration in hospitalized patients, but it is not known whether cholestyramine can be used as an antidiarrhoeal agent at an early stage of acute diarrhoea in outpatients. We conducted a randomized double-blind placebo-controlled trial of cholestyramine in infants aged 6 to 24 months with acute diarrhoea of less than one day's duration. The patients were given oral fluids from the beginning of diarrhoea, and normal feedings for age were reintroduced within 24 hours of treatment. Cholestyramine or placebo treatments $2 \mathrm{~g}$ twice daily were initiated as soon as oral fluid replacement was secured. The duration of watery diarrhoea in infants receiving cholestyramine $(\mathrm{N}=15)$ was $0.9 \pm 1.1$ days as compared to $2.9 \pm$ 1.5 days in those receiving placebo $(\mathrm{N}=25), \mathrm{p}<0.001$. Cholestyramine treatment was not associated with acidosis or hyperchloreamia. It is concluded that cholestyramine $2 \mathrm{~g}$ twice daily can be safely given to infants with acute diarrhoea and the treatment is effective in shortening the course of rotavirus or non-specific diarrhoea in such infants. 
CPZ is an antisecretory agent which has been used in the treatment of secretory diarrheas. We had previously shown that the drug neither interferes with glucose influx nor with its trans-mural fluxes in the in vitro rabbit ileum, while significantly lowering Pheny lalanine(PHE),Glutamic acid,Lysine and Glycyl-Phenylalanine influx. To further define such interaction, we have investigated the effects of CPZ on PHE influx and bidirectional transepithelial fluxes across stripped rabbit ileum in vitro. Results: 1) $0.2 \mathrm{mM} \mathrm{CPZ} \mathrm{(on} \mathrm{the}$ serosal side)reduces net transepithelial transport of $5 \mathrm{mM}$ PHE from $1.28 \pm 0.30$ (Control period) to $0.67 \pm 0.49$ (after CPZ) $\mu$ Moles $/ \mathrm{hr} . \mathrm{cm}^{2}$, means \pm S.E. $\left.(p<0.05) ; 2\right)$ PHE influx across brush border was measured at PHE concentrations ranging from 0.1 to $20 \mathrm{mM}$ in presen ce and in absence of $0.2 \mathrm{mM} \mathrm{CPZ}$; results show that CPZ significantly increases the $K_{t}$ of PHE transport (from 1.94 to $9.4 \mathrm{mM}$ ) while leaving unchanged its $V_{\max }$ (from 10.2 to $10.4 \mu$ Moles $/ \mathrm{hr} . \mathrm{cm}^{2}$ ); 3) $1 \mathrm{mM}$ PHEuptake measured in the presence of $\mathrm{CPZ}$ concentrations rang ing from 0.01 to $0.5 \mathrm{mM}$ showed that the effect of $C P Z$ was already maximal at $0.2 \mathrm{mM}$, with a half-maximal effect between 0.1 and 0.2 $\mathrm{mM}$. Conclusion: CPZ impairs PHE absorption by reducing its influx step with a competitive inhibition; the interaction of $\mathrm{CPZ}$ with other amino acids transport is currently being investigated.

H.K.Harms, R.M.Bertele, S.Rohrschneider, Univ.Kinderklinik München, FRG

The value of HBT during acute GE is a controversial subject (Gardiner AJ et al.,Arch.Dis.Childh.56,364(1981), Lifshitz CH et al. J.Pediatr.102,371(1983), Solomons NW et al., Acta Paed.Scand.,68, 171(1979)). We therefore compared the $\mathrm{H}_{2}$ productivity of stool specimen in vitro with the expired peak $\mathrm{H}_{2}$ concentrations every two days during acute infantile GE. - Breath $\mathrm{H}_{2}$ was related to breath $\mathrm{CO}_{2}$ as previously described (Harms $\mathrm{HK}$ et al.,Pediatr.Res. $15,1205(1981))$. We incubated the stool specimen $(0.13 \mathrm{~g})$ for 2 hours under anaerobic conditions (Argon) in PBS buffer ( $\mathrm{pH7} .4$ ) at $37^{\circ} \mathrm{C}$ with and without lactose $(0.016 \mathrm{~g})$ and evaluated the $\mathrm{H}_{2}$ volume released from lactose. - We studied 18 infants with acute GE; 11 were rotavirus positive. In 13 of the 18 patients $(72 \%)$ no $\mathrm{H}_{2}$ could be detected initially, neither in vitro nor in the expired air. This situation remained unchanged for 1-9days, on average 4.7 days. With amelioration of stool quality the $\mathrm{H}_{2}$ production normalized to an average of $57,3 \mu 1 \mathrm{H}_{2}$ in vitro and $25 \mathrm{ppm}$ in vivo. The stool specimen of 41 healthy infants, investigated for comparison, produced $47.3 \pm 7.6 \mu 1 \mathrm{H}_{2}$ in vitro.

According to our data HBT is of no value in yielding information about carbohydrate malabsorption during acute infantile GE.

MECHANISM OF THE EFFECTS OF MAGNESIUM ON SMALL INTESTINAL ION TRANSPORT. I Booth, P J Milla,

90 J Harries, G Stange, B Stieger, Hurer. Institute of Child Health, London and University of Zurich We have shown that increases in the concentration of $\mathrm{Mg}$, or the serosal addition of the divalent cation ionophore A23187 (under Ca-free conditions), both result in an increase in $\mathrm{Cl}$ flux from serosa to mucosa $(\mathrm{JCl} \mathrm{sm}$ ) in rabbit ileum in Ussing chambers. To investigate these observations further, the effects of potential inhibitors were studied together with the effect of $\mathrm{Mg}$ on brush border $\mathrm{Cl}$ transport in vitro.

The increases in short-circuit current $(p<0.001)$, potential difference $(p<0.001)$ and $J C_{s m}(p<0.01)$ which follow the addition of mucosal or serosal $\mathrm{Mg}(9.2 \mathrm{mmol} / 1)$ were not significantly altered by atropine $(0.3 \mathrm{mmol} / 1)$ or tetrodotoxin $(0.1 \mathrm{kmol} / 1)$. However, the $\mathrm{Mg}$-dependant increase in $\mathrm{JCl}$ sm $(p<0.001)$ which follows the addition of serosal A23187 was significantly inhibited by trifluoperazine $(0.1 \mathrm{mmol} / 1 ; \mathrm{p}<0.05)$. Brush border membrane vesicles were prepared from rabbit ileum pre-incubated in $\mathrm{Mg}(10 \mathrm{mmol} / \mathrm{l})$-Ringer's or control Ringer's. Rates of $\mathrm{Cl}$ uptake into vesicles (in the presence of $\mathrm{Na}, \mathrm{OH}$ or charge gradients) prepared from ileum pre-incubated with $\mathrm{Mg}$ did not significantly differ from controls. These data suggest that at least part of the cathartic effect of $\mathrm{Mg}$ is due to intracellular calmodulin activation; they provide no evidence to indicate an effect on neurotransmitter release, neuronal depolarisation or a direct action on brush border $\mathrm{Cl}$ transport.

DIAGNOSIS OF PROXIMAL SMALL BOWEL BACTERIAL OVERGROWTH IN CHILDREN. B. Descos, M.J. Martin,

91 J.P. Collet, C. Flandrois, P. Divry, G. Guillermet M. Hermier. Hôpital E. Herriot, Lyon, France. Diagnosis of proximal small bowel bacterial overgrowth is difficult to confirm. 18 investigations were performed on 12 children aged 2 months to 15 years ( 8 digestive surgical history, 3 Crohn, 1 coeliac with stasis). Each investigation consisted of :

- Bacterial count in jejunal juice aspirated at ligament of Treitz $\left((+)\right.$ : aero- or anaerobes count $\geqslant 10^{5}$ organisms $\left./ \mathrm{ml}\right)$.

- Fatty acids concentration (FA) in jejunal juice $((+)$,

Propionate $\geqslant 0.05 \mathrm{nM} / 1$ or Butyrate $\geqslant 20 \mu \mathrm{M} / 1$ ) (Chernov A.J. et al., Gut, $13: 103$ (1972)),

- Breath Hydrogen concentration (BTH) before and 15', 30', 45', $60^{\prime}$ after D-Xylose ingestion $(1 \mathrm{~g} / \mathrm{kg}, 5 \mathrm{~g}$ minimum $)(+(+)$ : increase of $\mathrm{BTH} \gg 10 \mathrm{ppm}$ ).

For obvious ethical reasons there were no controls.

Results : In 7 cases bacterial overgrowth was not detected by any method. In 7 cases its presence was proved by bacterial count with $(2+$ for FA and BTH, 1 + for FA, 2 + for BTH) or without ( 2 cases) product (FA or BTH) of bacterial metabolism. In the last 4 cases BTH alone was positive. Bacterial overgrowth was demonstrated more frequently by the detection of either metabolic product than by a bacterial count (respectively 9 and 7 ). Conclusions : In situations where bacterial overgrowth may be expected, using the above limits for normal in the 3 investigations, diagnosis of bacterial overgrowth remains difficult with any single method.

93

NALOXENE IS CYTOPROTECTIVE AGAINST INDOMETHAC IN INDUCED INTESTINAL ULCERATION RATS.

\section{G. Dinari, J. Weissman, H. Marcus, Y. Rosenbach,} Medical Center, Petah Tiqva, Israel.

Indomethacin (Indo) has been used for PDA closure in infants, but necrotizing enterocolitis may ensue. Naloxone ( $\mathrm{Nal}$ ), an opiate antagonist, is effective in shock, and may prevent gastric stress ulcers in dogs. We therefore investigated the effect of $\mathrm{Nal}$ on Indo-induced intestinal ulceration in rats. Indo, $30 \mathrm{mg} / \mathrm{kg}$, was given s.c. I hr after refeeding fasted rats. Experimental groups also received $1.2 \mathrm{mg} / \mathrm{kg} \mathrm{Nal}$ over $2.5 \mathrm{hrs}$. Total ulcer area, mucosal cAMP and prostaglandin (PG) were measured $24 \mathrm{hrs}$ later.

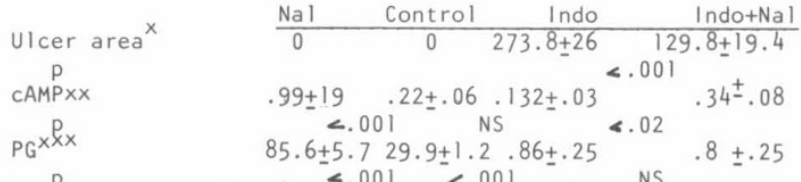

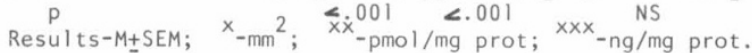

Nal was found to have a cytoprotective effect against the ulcerogenic action of Indo, and an increase in cAMP may contribute to that effect. Nal increased mucosal PG levels, but this does not seem to be the protective mechanism.

\section{4 ESTIMATED ${ }^{12}$ BY A NEW TECHNIQUE. K.Hjelt, P.A.Krasilni- koff. Dept. Pediatrics, Gentofte Hospital, University}

VITAMIN B ${ }_{12}$ ABSORPTION CAPACITY IN HEALTHY CHILDREN of Copenhagen, Denmark.

Most of the $\mathrm{B}_{12}$-absorption techniques are less usefull in children due to the need of cooperation and too high radioactive doses. We developed a method based on double isotope technique for use in children i.e. oral administration of $57 \mathrm{Co}^{-\mathrm{B}_{12}}$ and a nonabsorbed marker $5 \mathrm{CrCl}_{3}$. The fractional absorption of ${ }^{\mathrm{B}}{ }_{12}$ (FAB $\left._{12}\right)$ $=1-B_{i} \times A_{f} / A_{i} \times B_{f}$, where $B_{i}$ and $A_{i}$ are the amounts of ${ }^{12} 51 C r C I$ and $57 C_{0}^{1}-B_{12}$, respectively, given by mouth and $B_{f}$ and $A_{f}$ are the respective ${ }^{12}$ amounts in a single stool. The irradiation dose is very small. Calculation of $F A B$, based on measurements of a single stool corresponded to those fased on collection of all stools containing $51 \mathrm{CrCl}_{3}$. The reproducibility was estimated by duplicate determinations in 10 patients with malabsorption diseases. For a mean $\mathrm{FAB}$ of $10 \%$, SD was 2.8 . The maximal $\mathrm{B}, 12$ absorption capacity in different age groups of healthy children (recovered from malabsorption diseases) was estimated by use of oral saturation doses of $\mathrm{B}_{12}$. The maximal $\mathrm{B}_{12}$-absorption was estimated to $0.6 \mu \mathrm{g}$ $\left(1-3\right.$ yr, $\left.n \equiv{ }_{13}\right), 0.8 \mu \mathrm{g}\left(4-6{ }^{12} \mathrm{r}, \mathrm{n}=9\right), 1.1 \mu \mathrm{g}(7-10 \mathrm{yr}, \mathrm{n}=7), 1.5$ $\mu \mathrm{g}(10-15$ yr, $n=4)$.

The method proved very suitable in children. The result of the test expresses directly the absorption capacity of $\mathrm{B}_{12}$. This capacity increased throughout childhood due to increased capacity of ileum. 
The molecular pattern of plasma gastrins, the response of plasma big gastrin after milk feeding and the gastric secretion were investigated in 22 infants with hypertrophic pyloric stenosis (HPS). In addition, histochemical study of the antral gastrin cells was carried out. The pattern of plasma gastrins in HPS was closely similar to that in the normal infant and big gastrin was a dominant component of circulating gastrins. The mean big gastrin level in HPS was significantly higher that that of the controls both fasting and after feeding. Moreover, HPS also had hypersecretion of gastric acid. The number and the distribution of gastrin cells in the antral mucosa in HPS were similary found by immunostainings with two antisera, ant-bug gastrin serum and ant-gastrin serum. These gastrin cells were not different in number from those if infants and children with other diseases. These data suggest that the HPS has an incomplete negative feedback mechanism between plasma gastrin level and gastric acid secretion, and generally has hypergastrinemia of which trophic effect may play a role in the pathogenesis of this disease.

96

GLUCOSE ABSORPTION IN CONGENITAL GLUCOSE-GALACTOSE MALABSORPTION: A KINETIC BASIS FOR CLINICAL REMISSION E Wozniak, T R Fenton, J A Walker-Smith, P J Milla. $\overline{\text { Institute of Child Health, Queen Elizabeth Hospital }}$ and The Hospital for Sick Children, London

Glucose-galactose malabsorption (GGM) is an inherited disorder of carrier-mediated intestinal glucose transport. Previous studies have shown failure of microvillous membrane binding but paradoxically clinical amelioration may occur with increasing age. We have studied the in vivo absorption of glucose and fructose in the jejunum of five children (Age 1-14 yrs) with GGM and controls. In 8 control subjects glucose absorption obeyed saturation kinetics (appKm $76 \mathrm{mmol} / 1 \mathrm{Vmax} 25.6 \mathrm{\mu mols} / \mathrm{min} / \mathrm{cm}$ ). In GGM two groups of patients were discernible, GpA(n=2) with negligible glucose absorption and $\mathrm{GpB}(n=3)$ with marked depression of glucose absorption but still by a saturable process

(appKm 70 Vmax 3.7). Both groups were significantly different from controls $(p<0.001)$ and from each other $(p<0.001)$. One patient from GpB over a $4 \mathrm{yr}$ period developed some clinical glucose tolerance. No change was found in affinity for glucose by the transport process, appKm 75 and $80 \mathrm{mmols} / 1$; but maximal velocity (Vmax) increased from 4.2 to $10.2 \mu \mathrm{mols} / \mathrm{min} / \mathrm{cm}$.

These data suggest that at least 2 molecular variants of GGM exist, one where there are no functional transport sites and one where there are decreased numbers of normally functioning transport sites. In this latter group clinical remission may be due to increasing numbers of transport sites. 